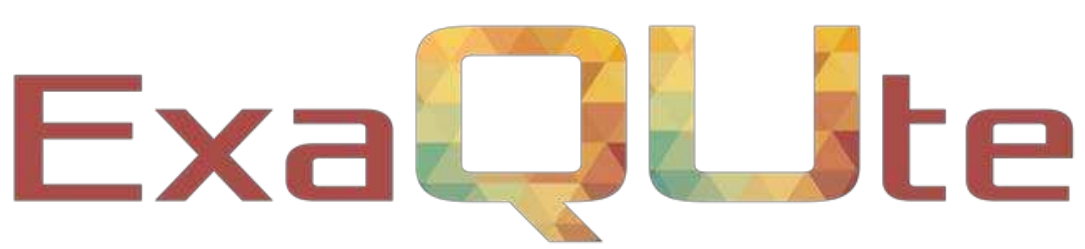

Exascale Quantification of Uncertainties for

Technology and Science Simulation

\title{
D8.2 Report on dissemination activities
}

\section{Document information table}

\begin{tabular}{|l|l|}
\hline Contract number: & 800898 \\
\hline Project acronym: & ExaQUte \\
\hline Project Coordinator: & CIMNE \\
\hline Document Responsible Partner: & CIMNE \\
\hline Deliverable Type: & Report \\
\hline Dissemination Level: & PUblic \\
\hline Related WP \& Task: & WP 8 Task 8.1 \\
\hline Status: & Final version \\
\hline
\end{tabular}




\begin{tabular}{|ll|}
\hline${ }^{\star \star \star}$ & This project has received funding from \\
${ }_{\star \star \star}^{\star}$ & the European Union's Horizon 2020 \\
${ }_{\star \star \star}^{*}$ & $\begin{array}{l}\text { research and innovation programme } \\
\text { under grant agreement No } \mathbf{8 0 0 8 9 8}\end{array}$ \\
\hline
\end{tabular}

\section{Authoring}

\begin{tabular}{|l|l|l|l|l|}
\hline Prepared by: & Partner & Modifications & Version & Comments \\
\hline Authors & CIMNE & create document & & \\
\hline Cecilia Soriano & & & & \\
\hline & & & & \\
\hline & & & & \\
\hline Contributors & All Partners & & \\
\hline All Partners & CIMNE & & \\
\hline Riccardo Rossi & & & \\
\hline & & & \\
\hline
\end{tabular}

\section{Change Log}
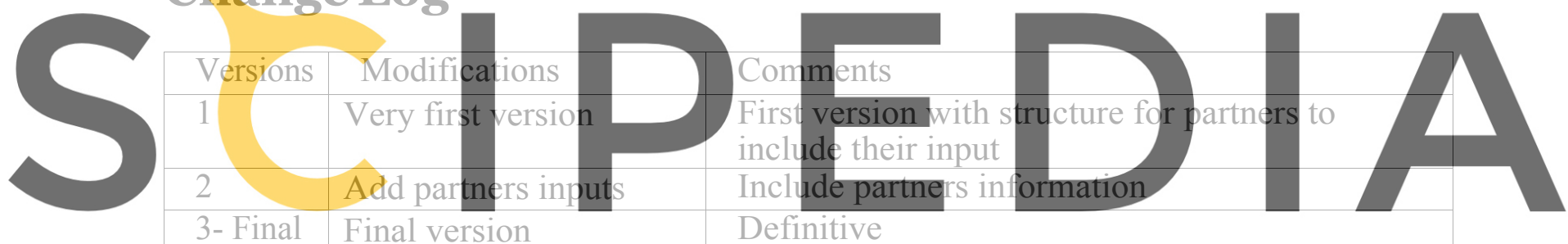

Register for free at https//www.scipedia.com to download the version without the watermark Approval

\begin{tabular}{|l|l|l|l|l|}
\hline \multicolumn{5}{|l|}{ Approved by: } \\
\hline & Name & Partner & Date & OK \\
\hline Task leader & Cecilia Soriano & CIMNE & $29 / 11 / 2019$ & OK \\
\hline WP leader & Cecilia Soriano & CIMNE & $29 / 11 / 2019$ & OK \\
\hline Coordinator & Riccardo Rossi & CIMNE & $29 / 11 / 2019$ & OK \\
\hline
\end{tabular}




\section{Table of contents}

1 Aim of the dissemination Plan in ExaQUte.............................................................4

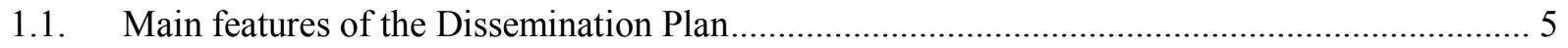

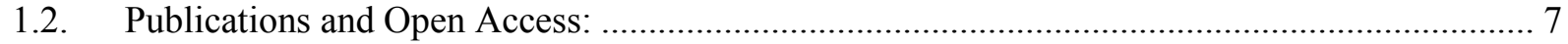

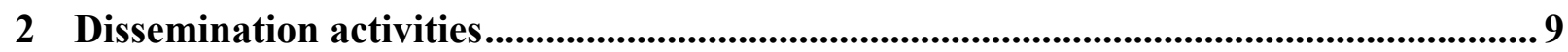

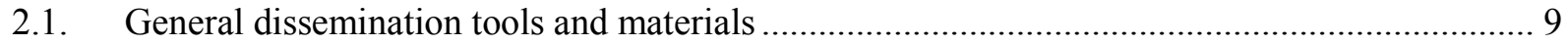

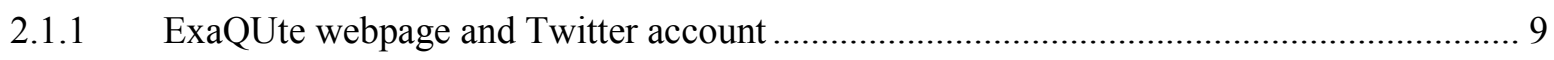

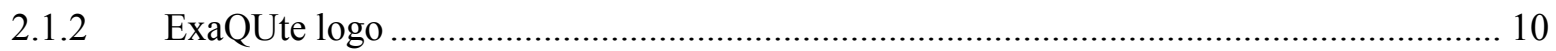

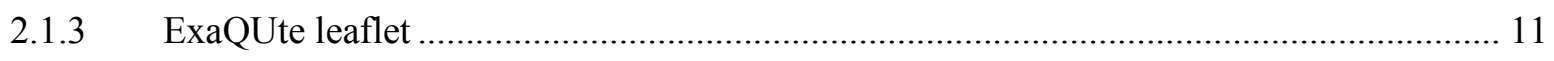

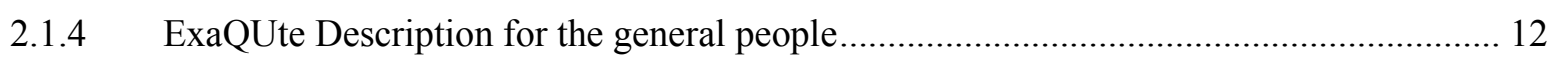

2.2. Common dissemination activities with EC Exascale research projects ................................. 13

2.2.1. EuroHPC Summit Week 2019 Poznan (Poland) 13-17 May 2019.................................. 14

2.2.2. ISC Conference 2019 (Frankfurt 17-19 June) ............................................................. 15

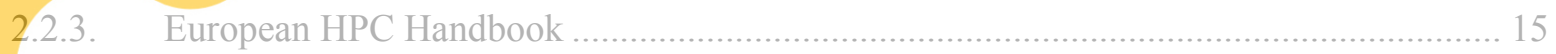

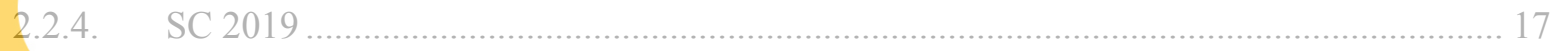

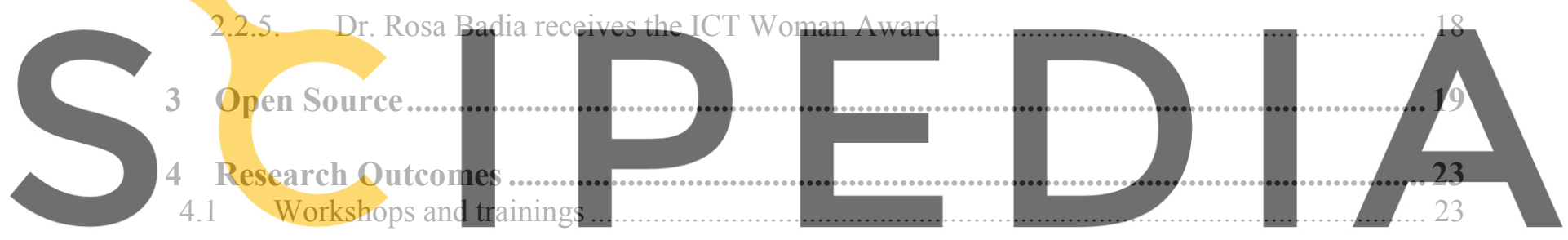

4.2 Publications in journals and communications in conferences .............................................29 Register for free at https//www.scipedia.com to download the version without the watermark 


\section{Aim of the dissemination Plan in ExaQUte}

Dissemination and exploitation of an $\mathrm{H} 2020$ project involves various activities that will bring research outcomes to the attention of as many relevant people as possible. Communication about European research projects should aim to demonstrate the ways in which research is contributing to Europe's leadership in innovation, science and technology. At the same time, it is a useful tool to account for public spending, by providing tangible proof that a collaborative research EU-funded project contributes to relevant results solving scientific and societal challenges.

Dissemination activities in ExaQUte are included in WP8 and are designed through a dissemination plan to be prepared during the first months of the project. The dissemination phase will start at the on-set of the project and will evolve as the different milestones are achieved. All partners will collaborate in the dissemination of the results among the different audiences (academic, industrial, administration, general public). All these activities will be agreed by the consortium.

The project will plan activities adequately resourced devoted to dissemination for specialized constituencies and general public, in particular for awareness and educational purposes. The dissemination plan deliverable has to consider adequate messages about the objectives of the project and its societal and economic impact.

The tools to be used should include web-based communication, press releases, brochures, multimedia material, use of social media etc. The dissemination material should be regularly updated to provide the latest version of the project status and objectives. Electronic and/or paper versions of this 'dissemination

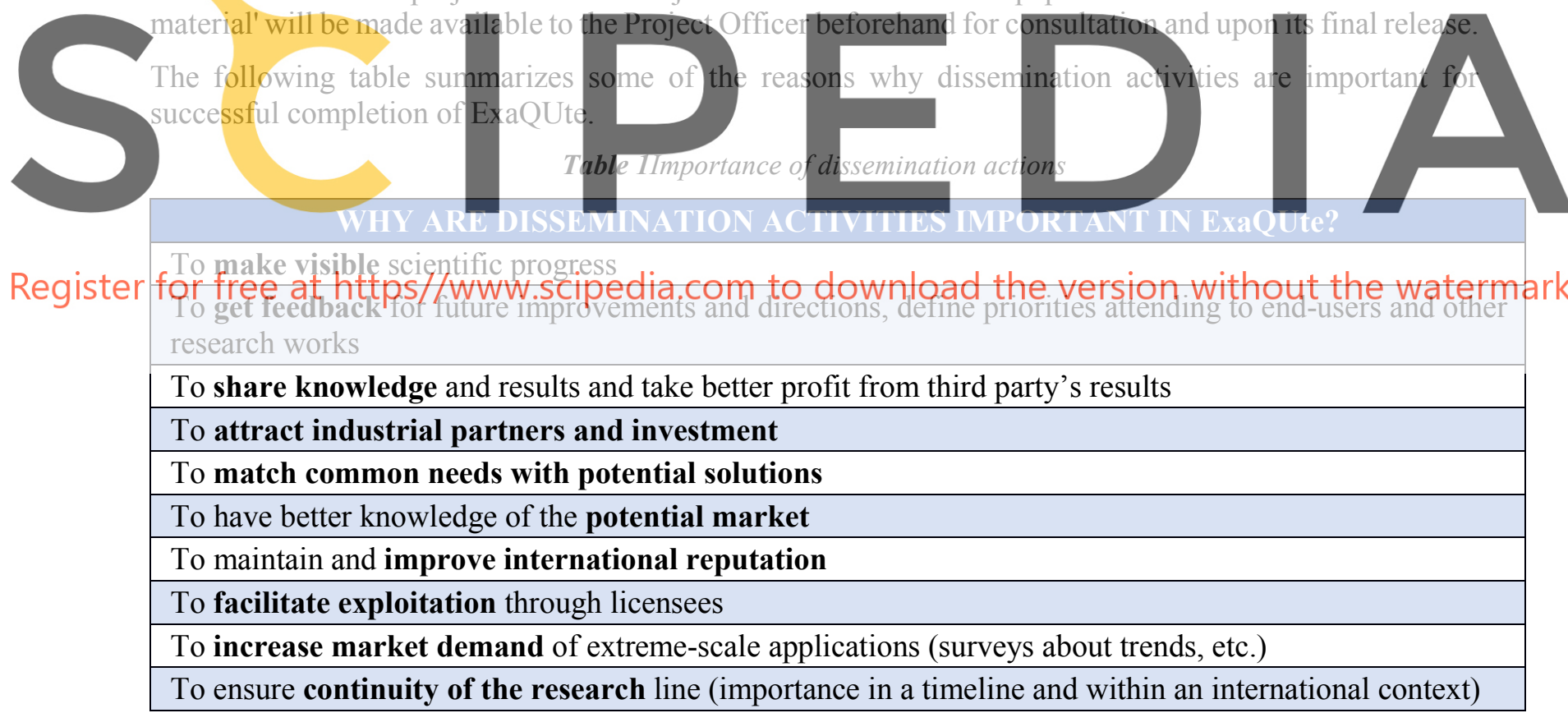

It is important to note that CIMNE has its own in-house specialized publication and congresses Departments, formed by a group of professionals with communication skills that will be involved in the ExaQUte dissemination and outreach activities. CIMNE also counts with a Network of Joint labs in Latin America (The CIMNE Classrooms Network) for cooperation in education and RTD activities, which can be used for dissemination overseas of the outcomes of ExaQUte through in-situ initiatives (details in www.cimne.com ).

\section{Different Audiences require different languages}

Dissemination of the project results will consist on the communication of the outcome of the project. The particular nature of this proposal and its ultimate application to the industrial world and its potential societal impact leads to the development of a multiple dissemination technical plan, targeted to different audiences.

The identified targeted audiences of ExaQUte include: 
- Specific HPC scientific exascale community, (i.e., calls FET-HPC and CoE and the rest of the European Exascale Projects Community researchers and PRACE people)

- Other scientific community, non HPC experts (end-users and application people, such as biomedical researchers, climate change researchers and so on)

- Industry (potential customers and end-users, such as aeronautic or civil engineering companies, etc.). Some of them have been already identified and participate in the ExaQUte User Panel.

- Universities (for training purposes, talented students and scientists, talking about what universities are doing in simulation and the growing interest of this field, how CAD/CAE is gaining weight in teaching)

- Government and decision-maker's agents. Due to the strategic intrinsic character that the HPC field has in the framework of the European Digital Agenda, it is important to make decision-makers aware of the outcomes of ExaQUte to ensure follow-up and better use of the results. (Crucial to adopt, for example, software-based solutions for climate change related problems, disasters, etc.)

General Public. Communication to a lay audience should also be accomplished, mostly through communication of the main results of the project and its societal implications

\subsection{Main features of the Dissemination Plan}

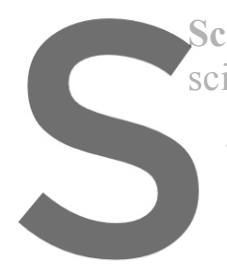

Scientific achievement

science and techinology,

- Attendance to scient

researchers. The con

results. Communicat
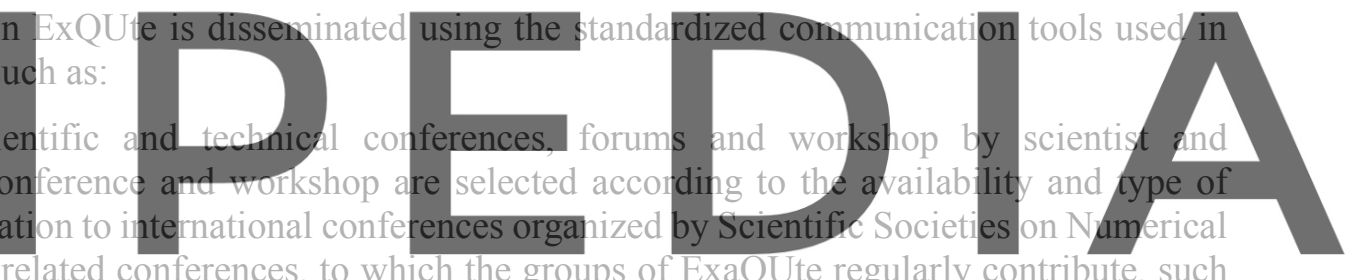

methods and HPC related conferences, to which the groups of ExaQUte regularly contribute, such

Register for free at https/www.scipedia, com to download. the version without the watermark

- ECCOMAS (European Community on Computational Methods in Applied Sciences),

- SEMNI (Spanish Association for Numerical Methods in Engineering),

- ERCOFTAC (European Research Community in Flow, Turbulence and Combustion).

- PARCFD (parallel Computational Fluid Dynamic)

- HPCC IEEE International Conference on High Performance Computing and Communications

- HiPC (IEEE International Conference on High Performance Computing)

- ISC High Performace, the International Supercomputing Conference

- PRACE Scientific Conference and User Forum

- The bi-annual series of SIAM conference on Geometric Design

- Conferences on Isogeometric analysis, IGA

- bi- annual series of SIAM conference on Uncertainty Quantification

- PASC (Platform for Advanced Scientific Computing Conference)

- SC The International Conference for High Performance Computing, Networking, Storage and Analysis

- IEEE Cluster Conference (Cluster)

- IEEE/ACM International Symposium on Cluster, Cloud and Grid Computing (CCGRID) 
- The project is actively participate in the concentration activities and meetings related with HPC and/or the e-Infrastructures area. The objective is to encourage synergies between projects and promote activities of common interest. The coordinators of ExaQUte and other ExaQUte partners have been involved in previous HPC project and have been/are already participating in coordination actions with the European Exascale Projects community.

- Organization of a specific session on HPC Adaptive meshing and evolving geometry and simulations in the framework of the ECCOMAS-European Research Community of Computational Methods in Applied Sciences (CIMNE belongs to the organizing committee of these conferences), in which some of the partners belong to the organization committees. It will represent an opportunity to put together a think-tank on this field with the involvement of world-class experts.

- Publication of scientific and technical papers in relevant scientific journals is a cornerstone of the results of the project. The publication of the project outcomes in peer-reviewed journal is also a way to give confidence to potential users and to demonstrate the soundness of the work, supported by the scientific community.

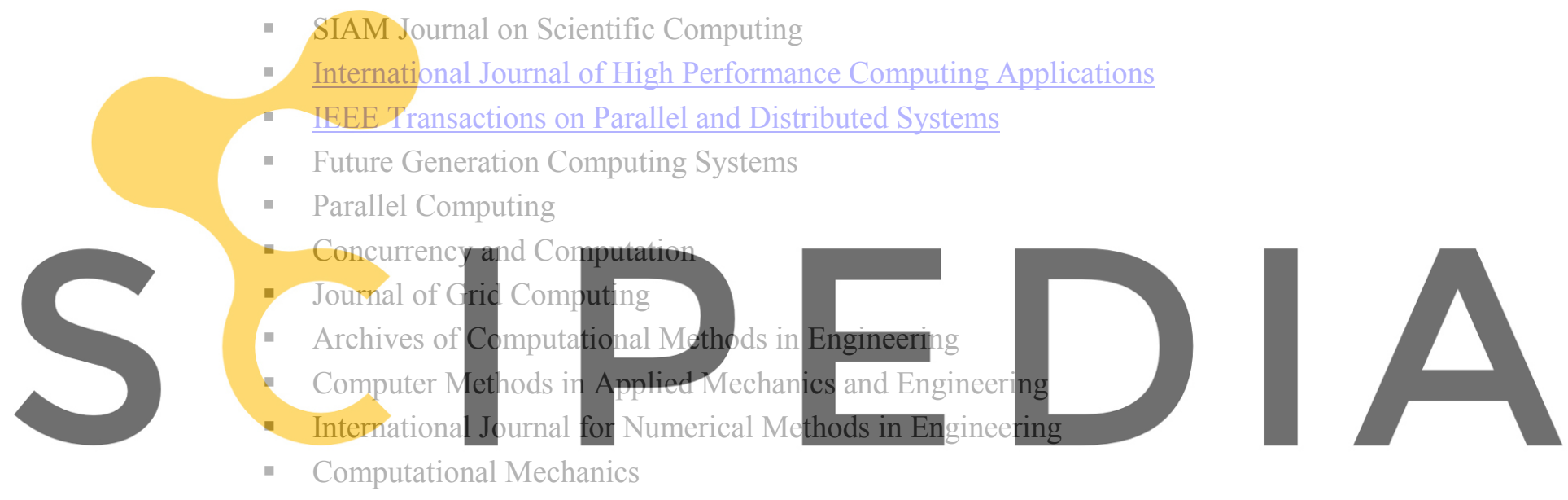

- Training sessions for partners and other scientists and code developers.

- Presentation of results of the project in form of dissemination material and practical demos at the SC and ISC-HPC events where BSC holds a booth.

- Final ExaQUte Workshop with participation of ExaQUte User Panel and other relevant stakeholders.

Regarding this last issue (training), examples of the actions to be implemented in the framework of ExaQUte are the GiD and KRATOS conferences regularly organized by CIMNE every two years. They represent an opportunity to bring together users and developers of the platforms in order to exchange ideas and experience, and receive direct feedback from users. The meeting is organized in a conference format including oral presentations and discussion on advances in the development and applications of GiD and KRATOS to different fields in engineering and science and to identify future directions for research and practice. Also, BSC organizes a regular yearly training on the PyCOMPSs/COMPSs programming model at the PRACE Advanced Training Center (PATC).

It is crystal clear that the specific outputs of the ExaQUte project (codes and know-how) are not of direct use for a general audience, and not even for a general scientific community (although the tools will for sure be used in the framework of very different fields of research, and its general impact, as described in the previous section, can be huge when applied to solve critical societal challenging problems).

Tentative users of the type of tools to be developed in the framework of this project are highly specialized modelers that have a chance to perform research and run their development in the top-rated supercomputing facilities in Europe (or elsewhere). 
Regarding specific communication issues between users of the new tools developed in ExaQUte, it is worth to highlight here the experience of CIMNE with the KRATOS and GiD community. GiD and KRATOS developers, together with their users, are a very active community in terms of collaborating and exchanging knowledge and experiences in their field, in the form of web-pages, mailing lists and wiki pages (as examples of this kind of communication, visit KRATOS's wikipage at: http://kratos-wiki.cimne.upc.edu and GiD mailing list repository at http://www.gidhome.com/support/mailing-list). In these spaces, users of the codes exchange communications about encountered troubles, "tricks" or needs.

This type of feedback is very valuable to the software developers, since they keep them updated of the necessities raised by users and helps them to improve their codes. Following the successful KRATOS and GiD dissemination philosophy, ExaQUte uses similar tools to ensure best spreading and tuning of the outputs of the project, ensuring its extension and continuity after the end of the project.

General communication of the projects' results to the non-scientific audience will be pursued by adapting the contents to the audience towards it is intended. Some of the envisaged actions, especially dedicated to the uptake of the outcomes of the project by the industrial sector, are the following:

\section{Public presentation events to potential users and industries. The consortium will organize public} events where the new tools will be presented;

\section{Publications in trade press and presentations in industrial fairs;}

Market-oriented publications in magazines and marketing material produced by partners' press office; Contact with Administrations and policy-makers (either at the regional/national/European level) involved in decision-making related to the efforts carried out to implement and exploit HPC

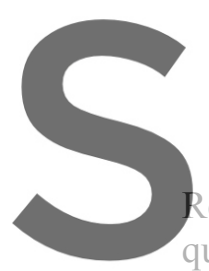
infrastructures
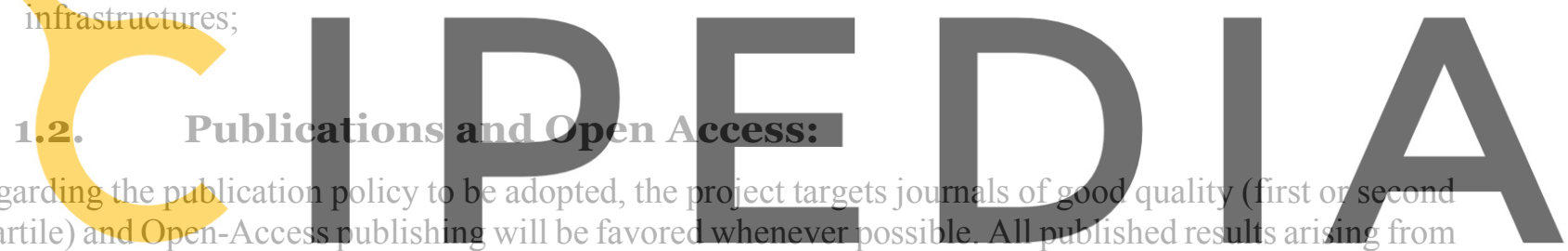

the research funded under ExaQUte are openly accessible, in accordance with Horizon 2020's mandate on

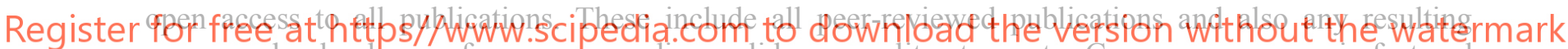
monographs, books, conference proceedings, slides, grey literature, etc. Green open access is fostered among partners, where post prints or publishers' PDFs of the research publications will be made available through one or more of the partners' institutional repositories, at no charge, and after an embargo period of between zero and six months has elapsed, depending on publisher policy. A strict self-archiving policy has been adopted, using open channels (for example Research Gate, university webpage, etc.).

ExaQUte embraces the initiatives of the European Commission to promote the open access to research data, aiming to improve and maximize access to and re-use of research data generated by Horizon 2020 projects. The main platform (project repository) to be used to publish and grant open access to the research data will be Scipedia (www.scipedia.com). Scipedia is an innovative scientific and technical digital publisher platform and professional social network promoted by the coordinator CIMNE. In this platform, a specific collection will be created for the project. This collection will gather the different research reports, published papers, along with the rest of the data generated in the project and selected to be openly available according to the DMP. Scipedia will ensure that the published content of the project is harvested by OpenAIRE aggregator, as a way to ensure compliance with the EC's policies on Open Access. The published data can optionally be additionally stored in the repositories of the project partners.

Aligned with those initiatives, a Data Management Plan (DMP) has been designed for ExaQUte project. A first version of this plan has been produced at the beginning of the projects as a deliverable released (D8.1) on M6 of the project, which can be updated during the project if necessary.

PU documents related to this project will be uploaded to the ExaQUte customized repository created under the Open Science Platform Scipedia, available at https://www.scipedia.com/institution/exaqute.eu, a snapshot of which is shown in Fig. (1). 


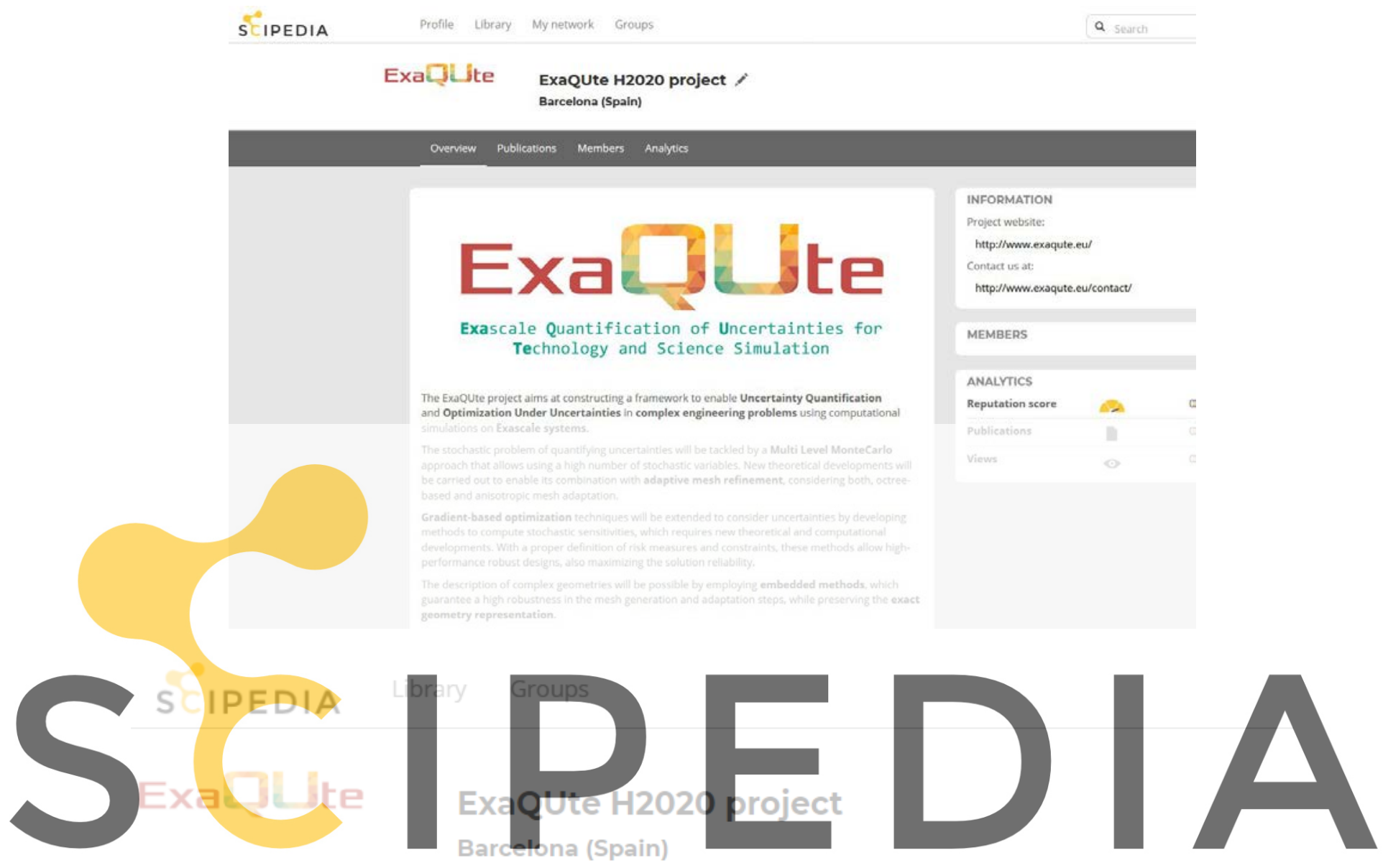

Register for free at https//www.scipedia.com to download the version without the watermark Overview Publications Members Analytics

Open Access Repository of the ExaQUte project Scope

This is the Open Access repository of the project "Exascale Quantification of Uncertainties for Tecnology and Science Simulation (ExaQUte) funded by the European Union's Horizon H2020 research and innovation [...]
2
(2) 0
จ $5 / 5$
READ

Figure 1: Scipedia repository to share open documents 


\section{Dissemination activities}

\subsection{General dissemination tools and materials}

\subsubsection{ExaQUte webpage and Twitter account}

The main dissemination tool of the ExaQUte project is it website www.ExaQUte.eu, created and made public a few weeks after the onset of the project. A snapshot of its home page is show in Fig.2\&3.
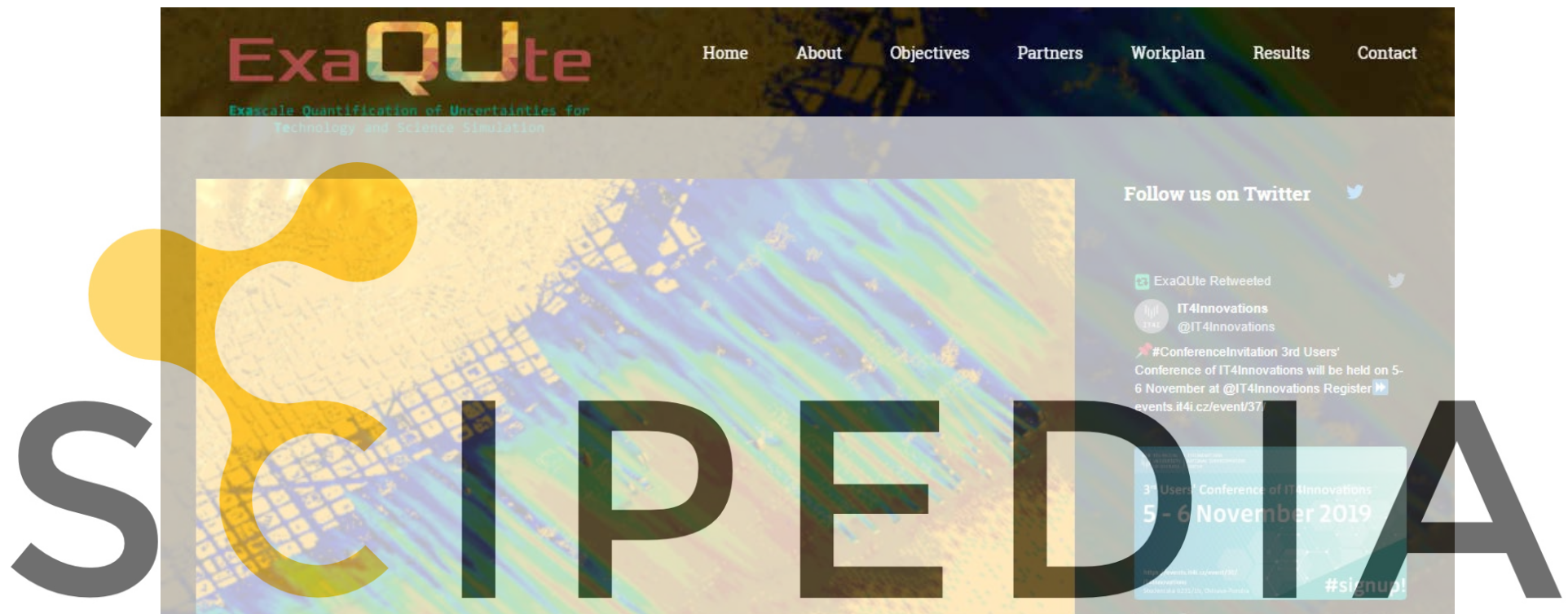

Register for free at https//www.scipedia.com to download the version without the watermark

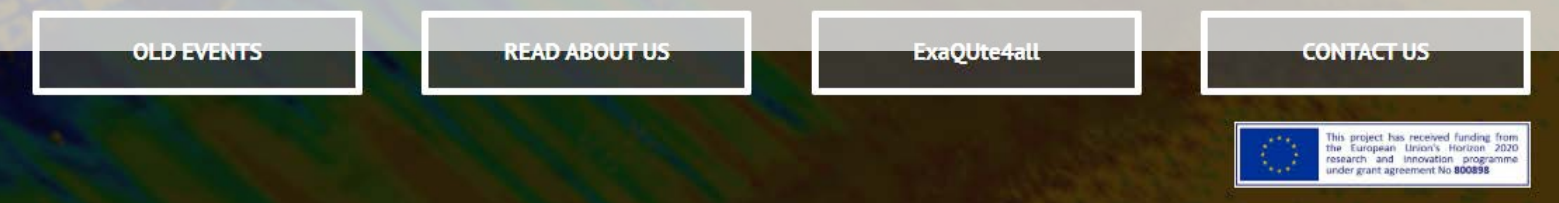

Figure 2 ExaQUte main webpage
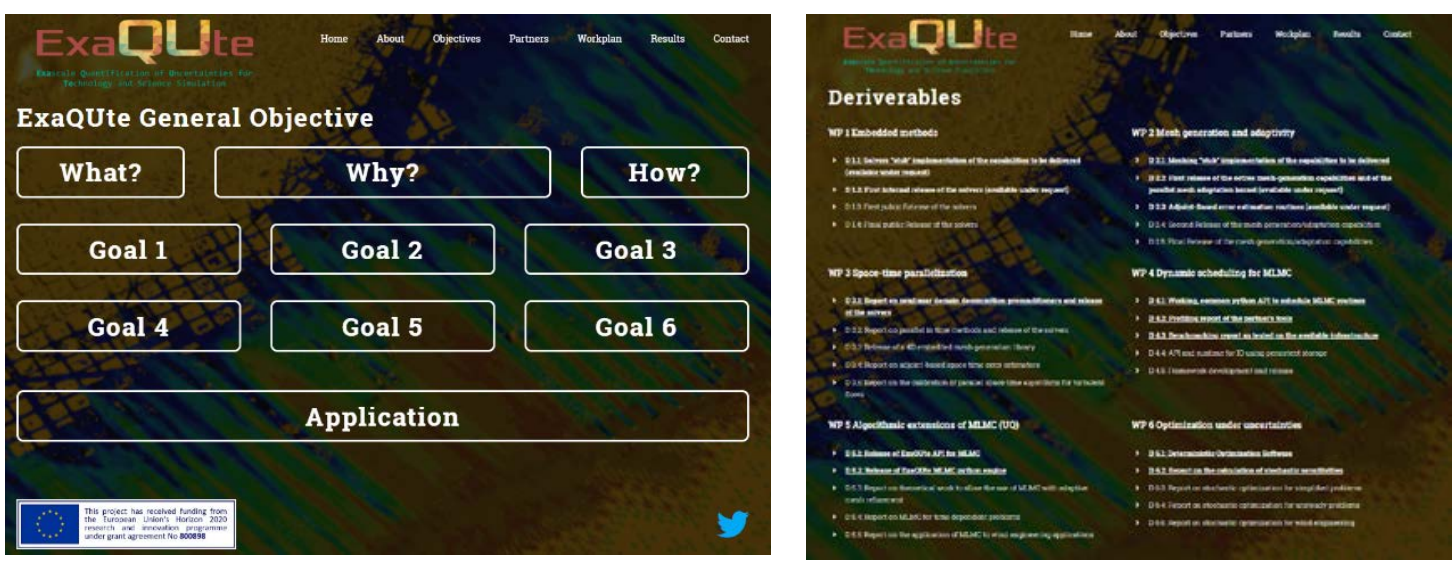

Figure 3 Snapshots of ExaQUte webpage 
In parallel, a twitter account (@ExaQUteEU ) was created to announce in a more dynamic way activities of the project or information relevant for people interested in HPC research.

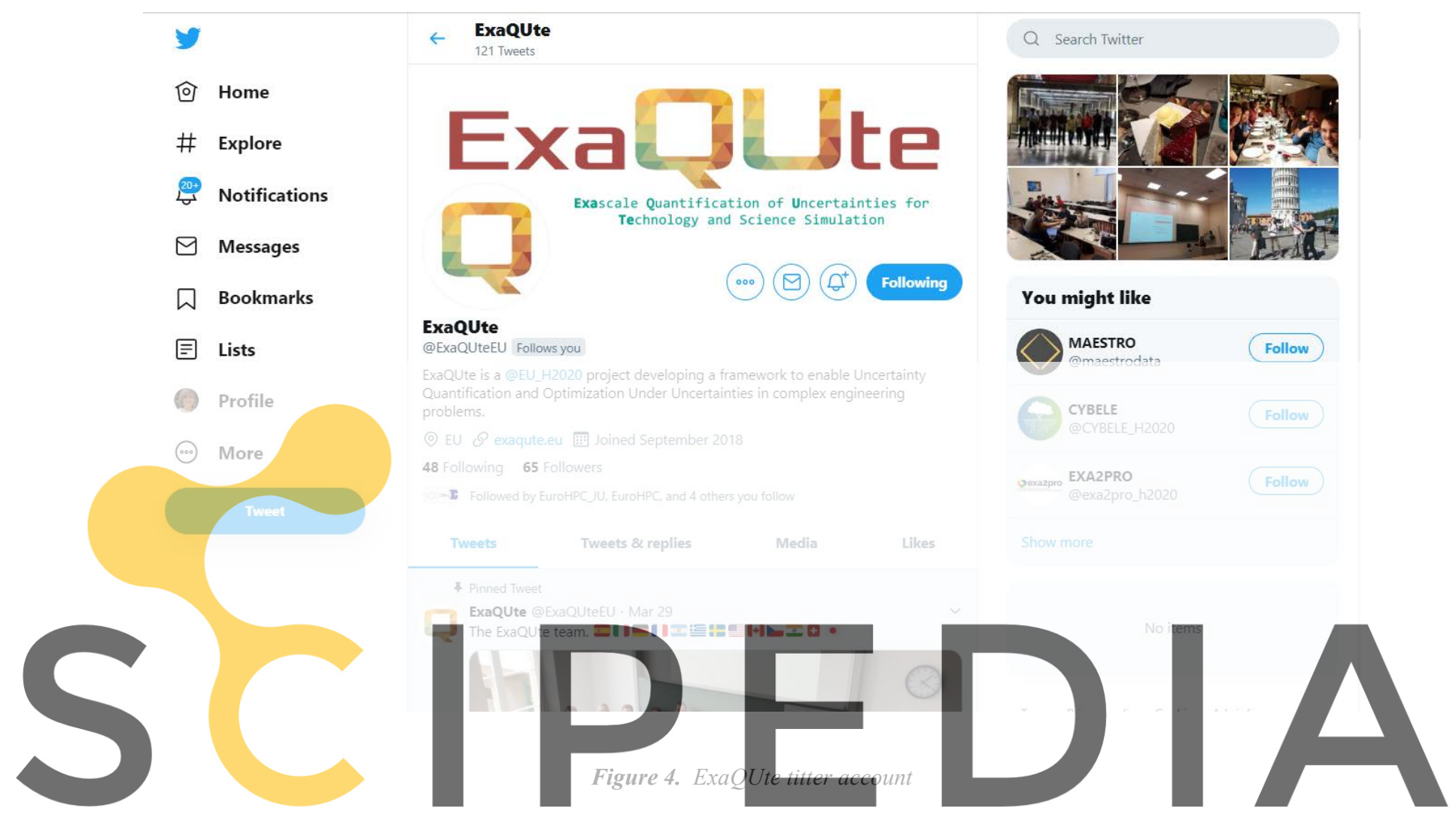

A "corporative" logo was also created for ExaQUte, whose design, more than just images and words, had to be able to tell a story about our project: what we do and what the project stands for.

Professionals at CIMNE's Publications Department were able to extract the very essence of ExaQUte from a short summary of the projects and a list of keywords, and summarized the key objective of NUMEXAS in one of its main tasks: SIMULATION.

The materialized visualization of this top feature of ExaQute was represented in the created logo through a simulation mesh symbol, which was integrated in the project's name by its use as the filling of the capital letters UQ, which stand for Quantification and Uncertainties, key issues in the project. The result of this conceptualization work is a new logo (Fig.5), self-contained in the project acronym/name, which was quickly accepted by the whole consortium.

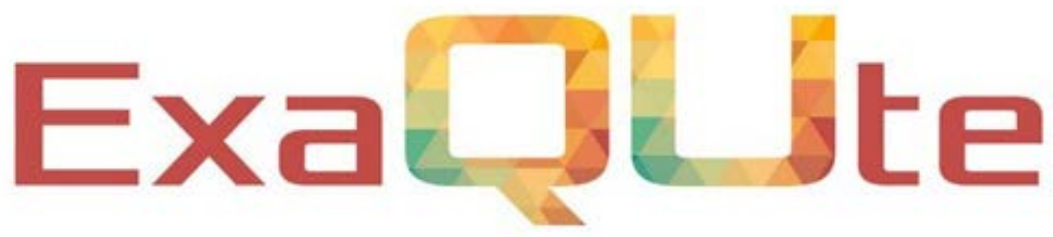

\section{Exascale Quantification of Uncertainties for Technology and Science Simulation}

Figure 5 ExaQUte logo 


\subsubsection{ExaQUte leaflet}

A leaflet diptych was also produce to have some physical support to be handled to visitors of the different participating institutions or as take-away material to be used in conferences/workshops/seminars or any other type of event.

The leaflet (Fig. 6 a,b) has been designed to be attractive to all type of audiences, highlighting the main objectives of the project, its structure and its application outcomes. Project's facts and Contact information is included, encouraging more specialized audiences to address their enquires and get more information.

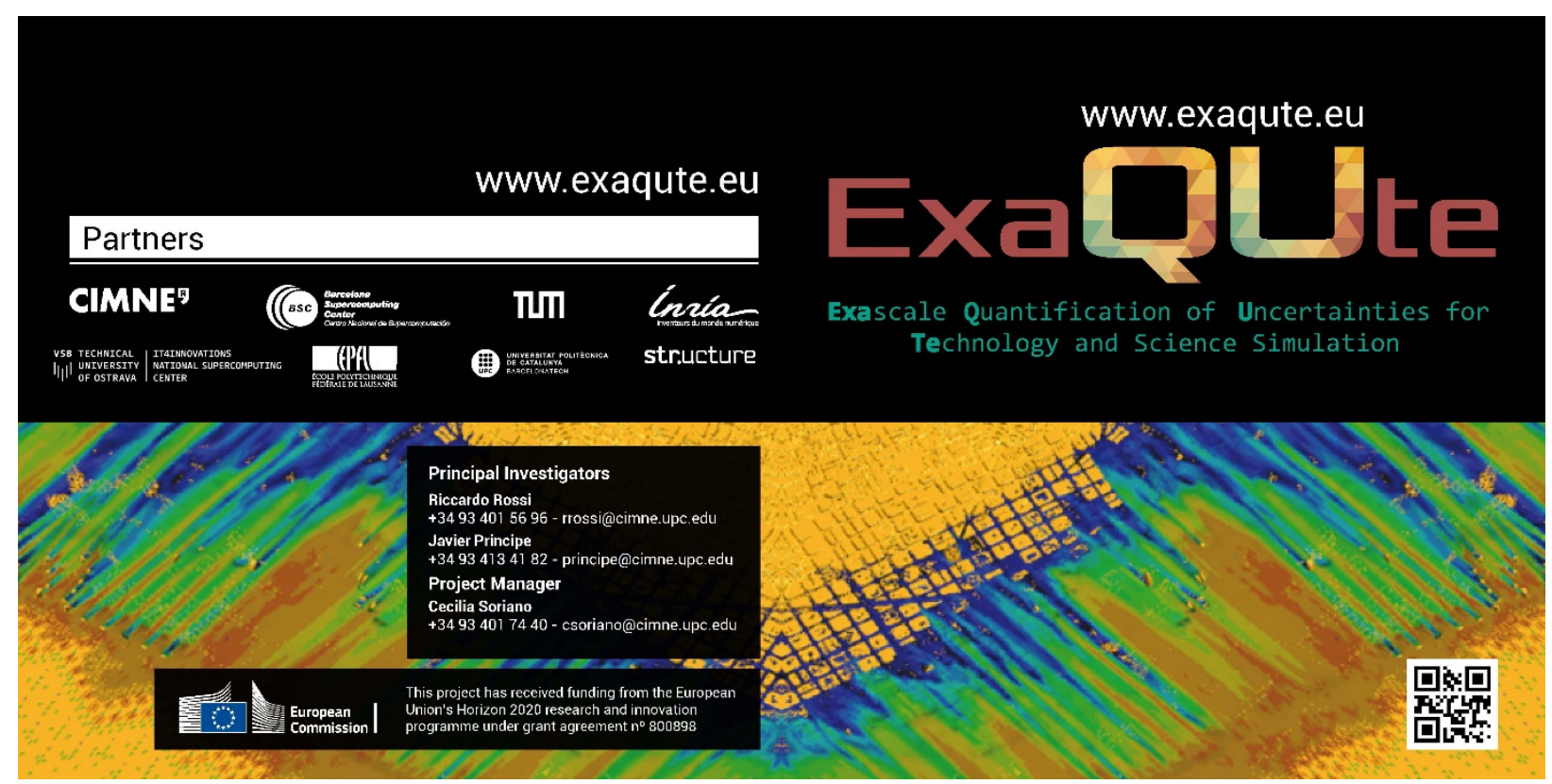

Figure 6a. External pages of ExaQUte's Diptych

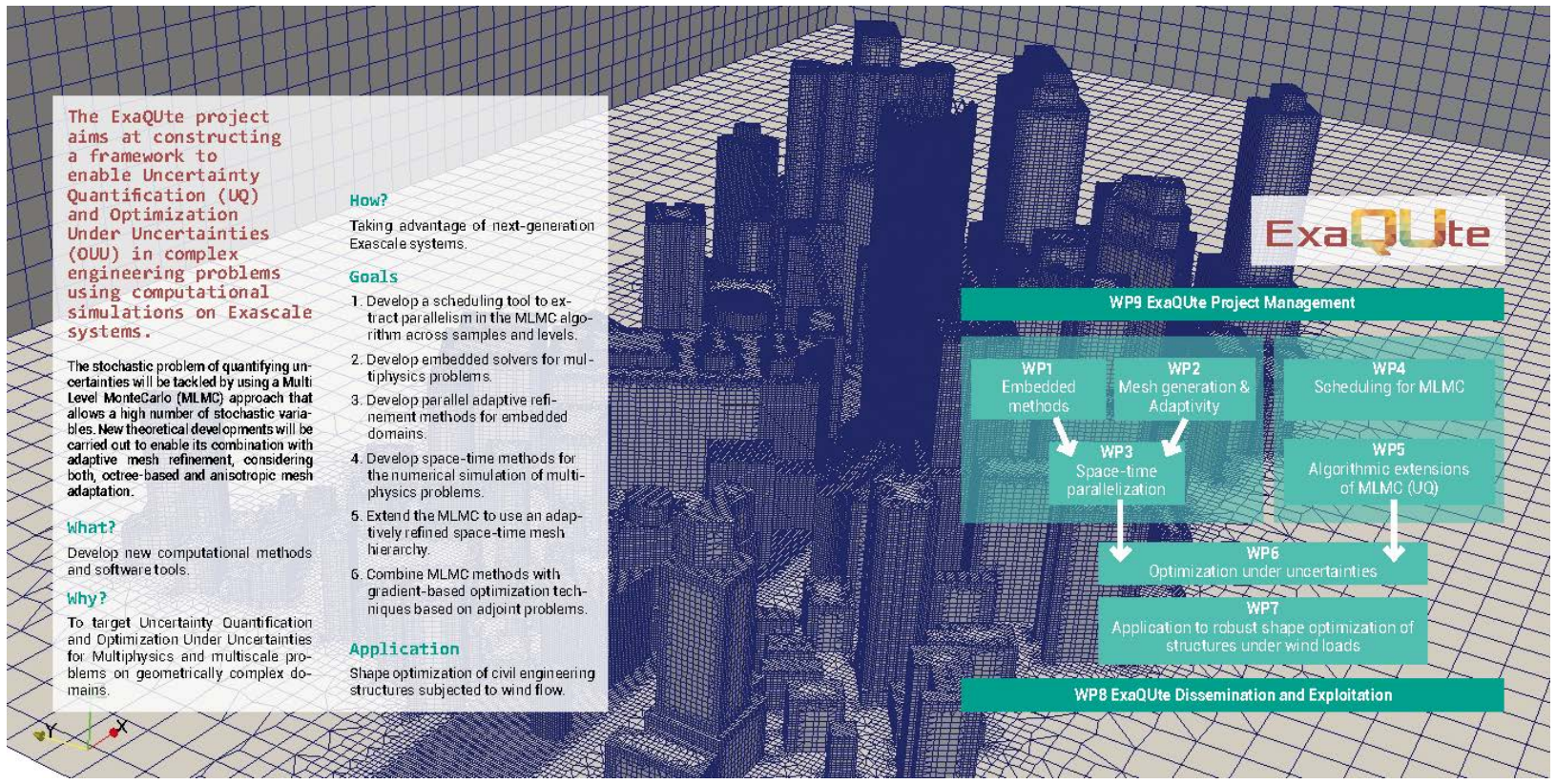

Figure 6b. Internal pages of ExaQUte's Diptych 


\subsubsection{ExaQUte Description for the general people}

Since different audiences require different dissemination material, we have produced a document describing the goals of ExaQUte in a comprehensive way for non-scientific

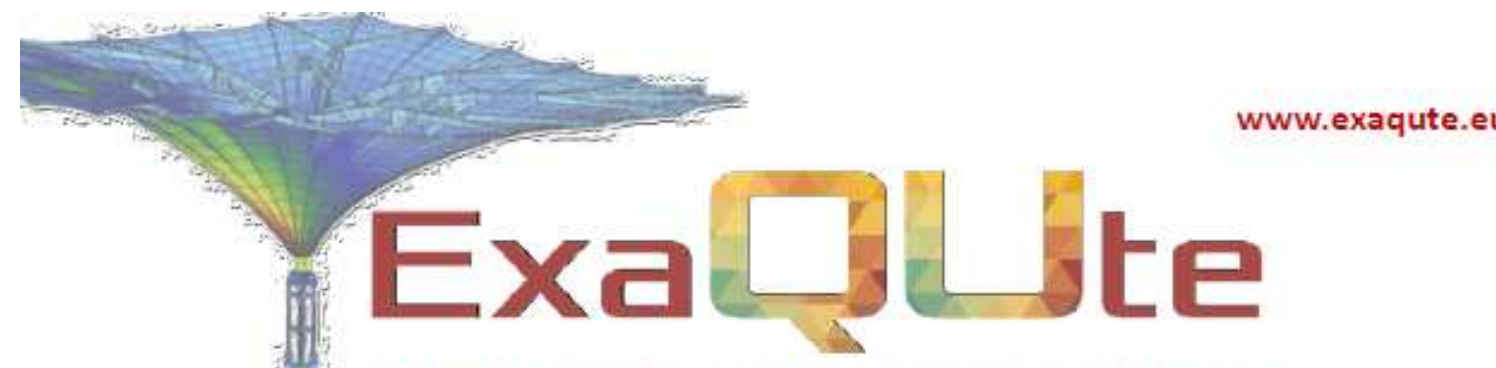

\section{Exascale Quantification of Uncertainties for Technology and Science Simulation}

Recent advancements in high performance computing (HPC) will soon allow for the use of exascale systems in industrial practice, bringing the immense computational power of today's machines to real engineering applications. The ExaQUte project aims at exploiting such systems, pushing our current physics simulation capabilities by performing Uncertainty Quantification (UQ) and Optimization Under Uncertainties (UQQ).

If we analyze the performance of current simulation tools, nowadays we can use numerical methods to accurately simulate and predict the behavior of a real phenomenon (for instance the interaction of structures and fluids, such as a building and the wind), provided that the values of relevant parameters at the initial state from external contributions to the system are known beforehand. This type of analysis can be costly for large and accurate cases, such a whole high-rise building, but it is still doable with our current technology.

Why dealing with uncertainty?

Uncertainty comes into play when some of the input parameters of our problem are not exactly known a priori. Then, since the inputs for the simulation are not exact, the solution of the problem we are simulating

\section{Tossing a coin}

A way to visualize the concepts of uncertainty and parallelism is by thinking of the example of tossing a coin. In an ideal set up, when tossing a coin a set number of times, and always in the same exact way, it would land on the same side every single time. However, in reality, there are many factors that are uncertain, such as the action of the air when the coin is moving, or shaking the hand. This leads to a certain proportion of heads and tails that will depend on all the external factors that contribute to the system. To obtain these exact percentages, one should think that the more throws, the more accurate the result.

For the sake of argument, consider that a hundred throws are enough to fully describe this behavior. In case you are asked to do this experiment by yourself, it will take you some time to toss the coin repeatedly until reaching the 100 th-experiment. If instead, 99 colleagues come to help you, you will have the analysis finishedinonesingle go. This is the concept of parallelism.

Following the coin example, ExaQUte aims at understanding the relation between the uncertainty (shaking of the hand, action of air) and final result (head or tail), in the smallest possible amount of time (parallelism).

Optimize the simulation results while taking into account uncertainty

Moreover, provided that we are able to model an uncertain phenomenon such as wind, in the same way as the coin example, how can we use this knowledge in engineering? How can we exploit the uncertain solution? Is it possible to use this result to optimize the shape of buildings accordingly?

ExaQUte will answer this final question by combining the concept of uncertainties with optimization. Typically, optimization is used to find the optimal design that yields the best performance for a given analysis with a specific set of inputs and parameters. This, however, may result in fragile des gns that are only adequate for the set of conditions they were conceived for. In this regard, the information given by uncertainty quantification allows us to converge to a final robust design-which tak finto account a wide range of different and uncertain conditions.

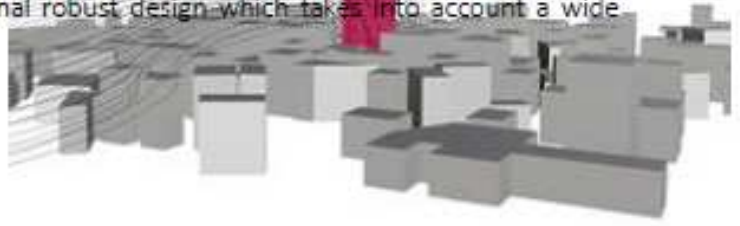




\subsection{Common dissemination activities with EC Exascale research projects}

As we learn from CIMNES's former exascale project NUMEXAS, specific emphasis was put by the EC to develop coordinated actions (both form the scientific and the dissemination point of view) with the rest of on-going EC projects in the areas of exascale computing.

Following this recommendation, still encouraged by the European Commission, ExaQUte joined the joint dissemination group of all the EUROPEAN EXASCALE PROJECTS AND INFRASTRUCTURE, composed of all the EC projects awarded in EC exascale calls.

The group has created a joint landing page to have access to all the participating projects https://www.montblanc-project.eu/euroexascale

Find below the projects that participate in this initiative

\section{European Exascale Projects and Infrastructure}

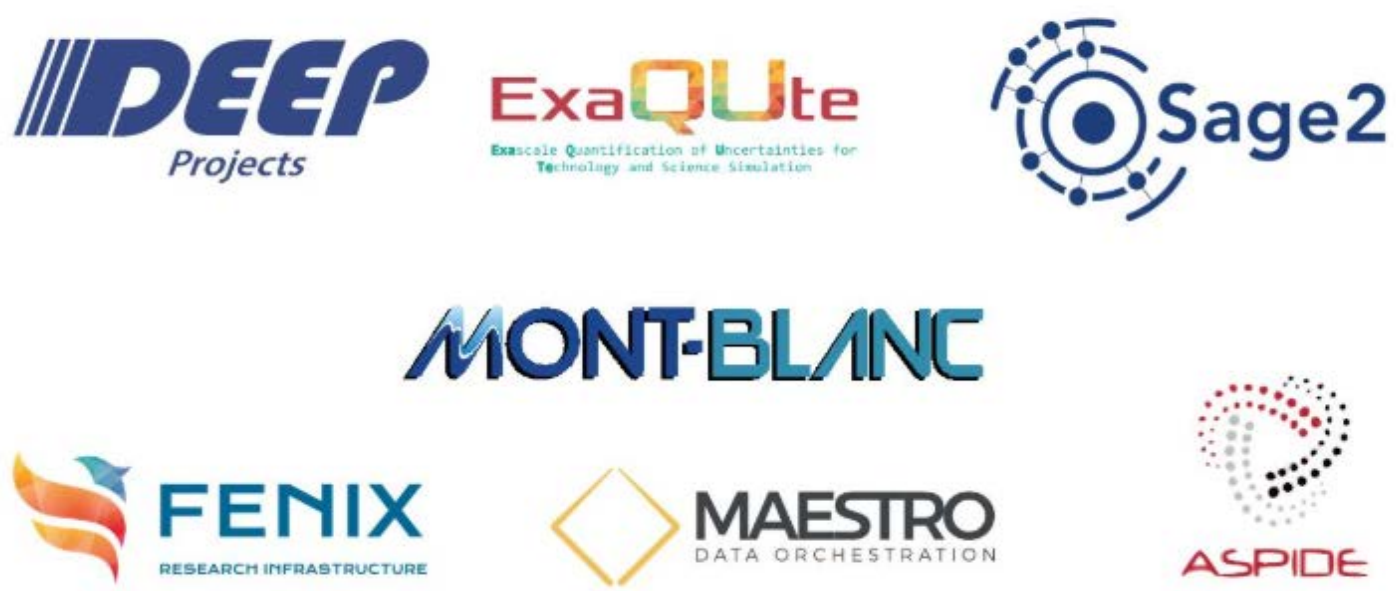

As members of the joint European exascale projects and infrastructure coordination and dissemination group, representatives of ExaQUte have attended the teleconferences that the group holds every other week.

Since ExaQUte joined the group, we have been actively participating in the joint conference calls and activities of the group, the main on which had to do with the preparation of Joint activities related to conference, workshop and training 
2.2.1. EuroHPC Summit Week 2019 Poznan (Poland) 13-17 May 2019

ExaQute was present at EuroHPC Summit Week 2019 held in Poznan (Poland) on 13-17 May 2018.

In this event, an ExaQUte poster was displayed and Rosa M Badia (BSC) was one of the presenters in the plenary on Wednesday, covering PyCOMPSs programming model aspects related to the project.

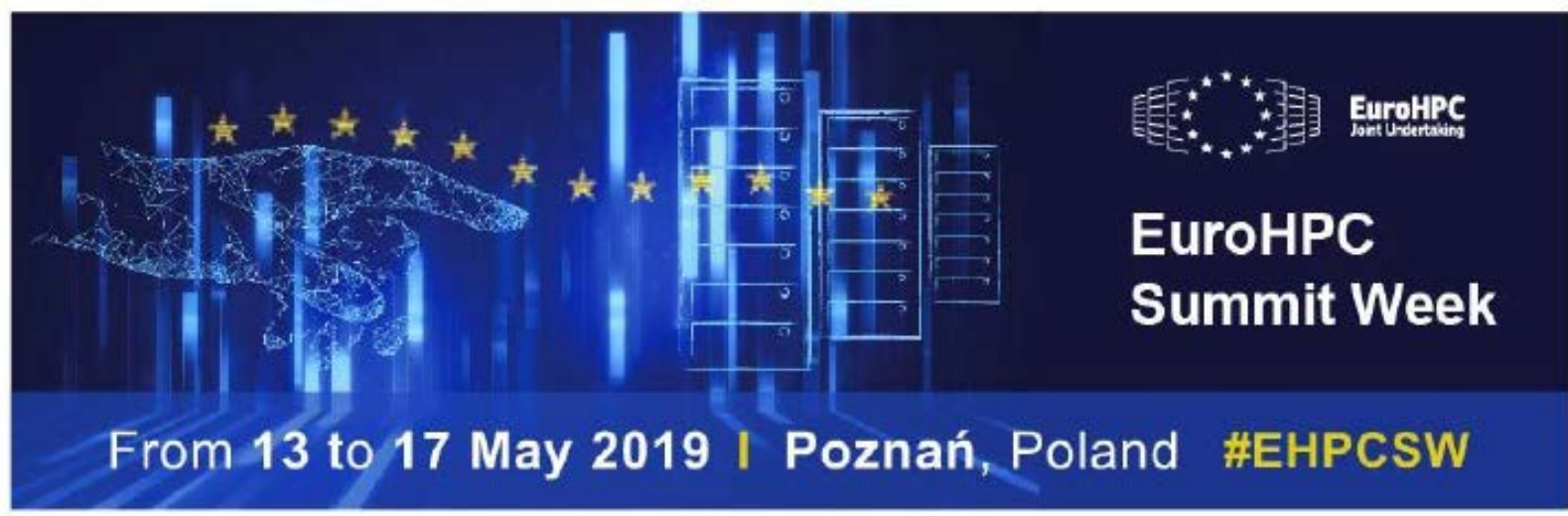

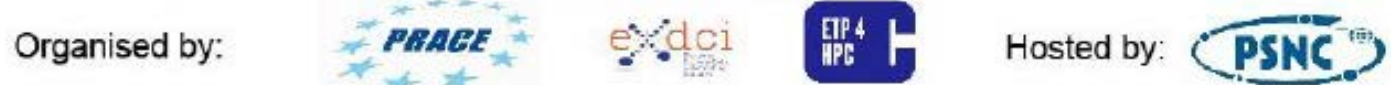

European Exascale Projects and Infrastructure MONT-BLANC EUROPEAN MODULAR AND POWER-EFFICIENT HPC PROCESSOR

ASPIDE
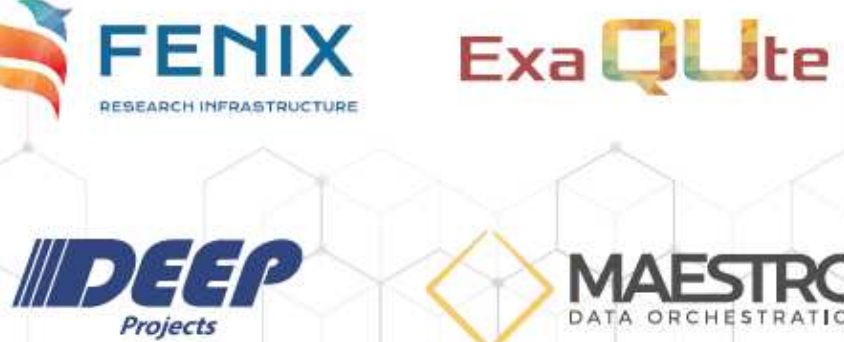
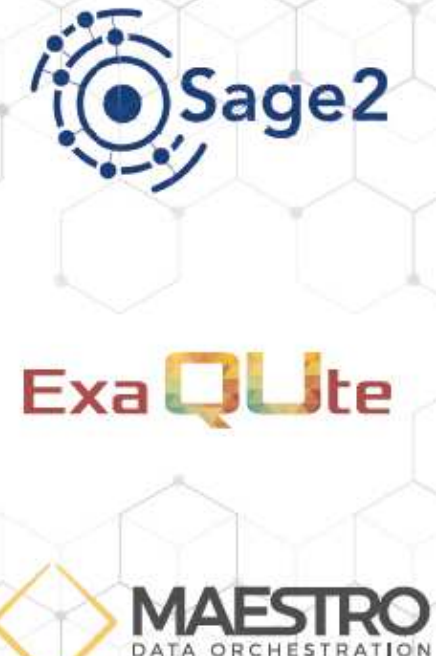

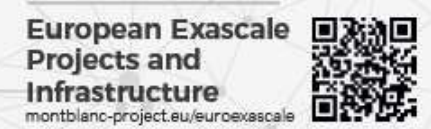

MONT-BLANE

FENIX

Exa पुLte marcole parntification of uncertainties for

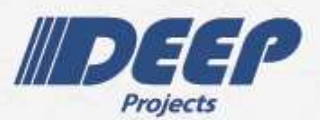

MAESTRO
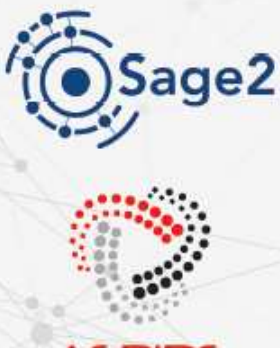

ASPIDE

Figure 7. Microfiber cloth for screens and bookmark for all EC Exascale Projects 2019 


\subsubsection{ISC Conference 2019 (Frankfurt 17-19 June)}

ExaQUte was present at ISC Conference 2019 in Frankfurt and joint the booth with other EC exascale projects.

The booth was attended by ExaQUte partners that were able to present initial project results and network with other ISC participants. BSC also participated in that event with its own booth, where general dissemination about the project was delivered, as well as PyCOMPSs demonstrations
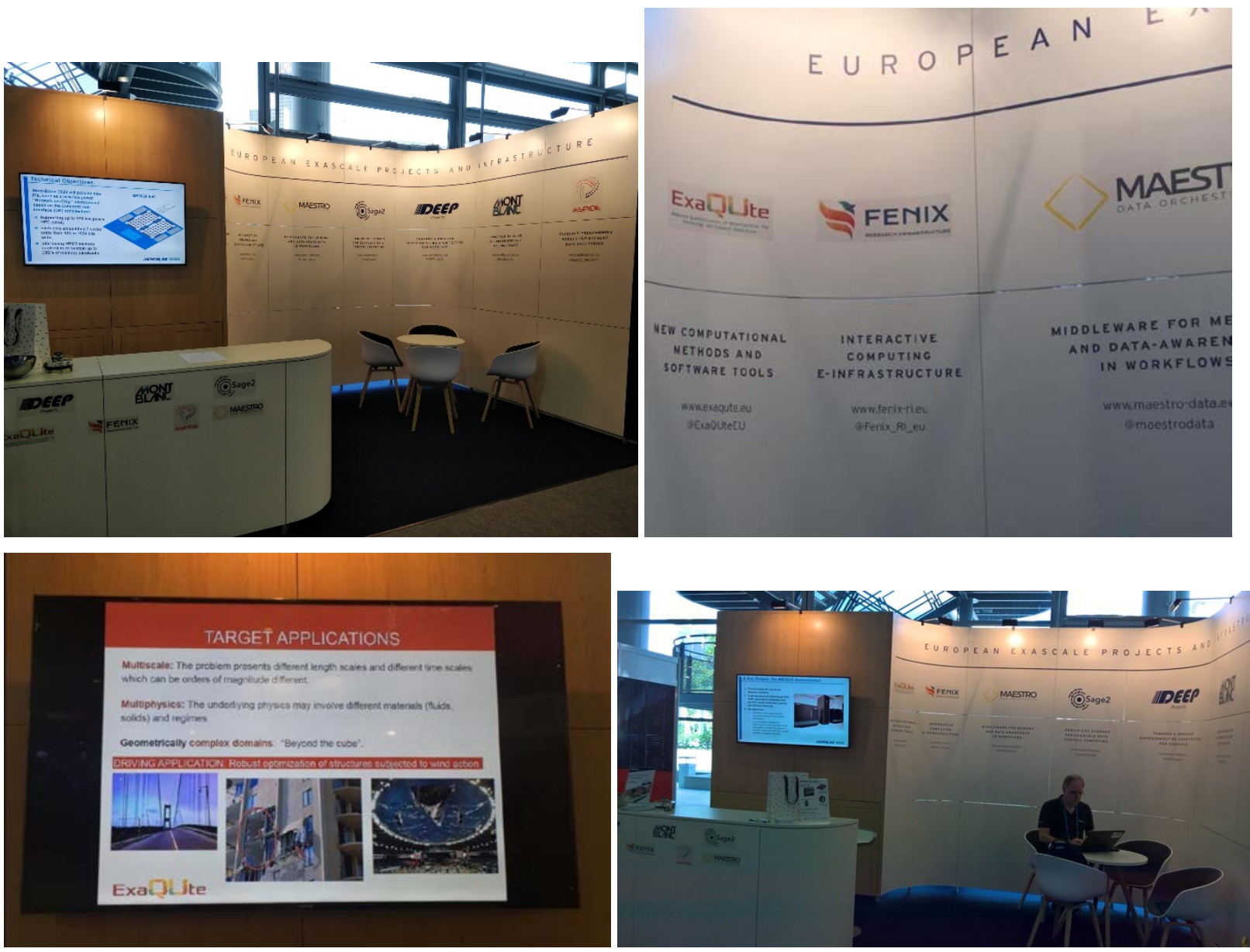

Figure 8 Common European Exascale Projects booth at ISC Conference 2019

\subsubsection{European HPC Handbook}

ExaQUte has been included in the European HPC Handbook, 2018 and 2019 Edition https://www.etp4hpc.eu/pujades/files/ETP4HPC Handbook 2019 web.pdf

The Handbook, that is updated every year, is an overview of the European HPC projects. Its increasing size is a sign of the vitality of the European HPC landscape. The Handbook now includes, besides the traditional projects financed by HPC cPPP-related calls, other projects 
closely related to HPC, such as HPC and Big Data testbeds, international cooperations, and naturally the European Processor Initiative(EPI).

\section{https://www.etp4hpc.eu/pujades/files/ETP4HPC_Handbook_2019_web.pdf}
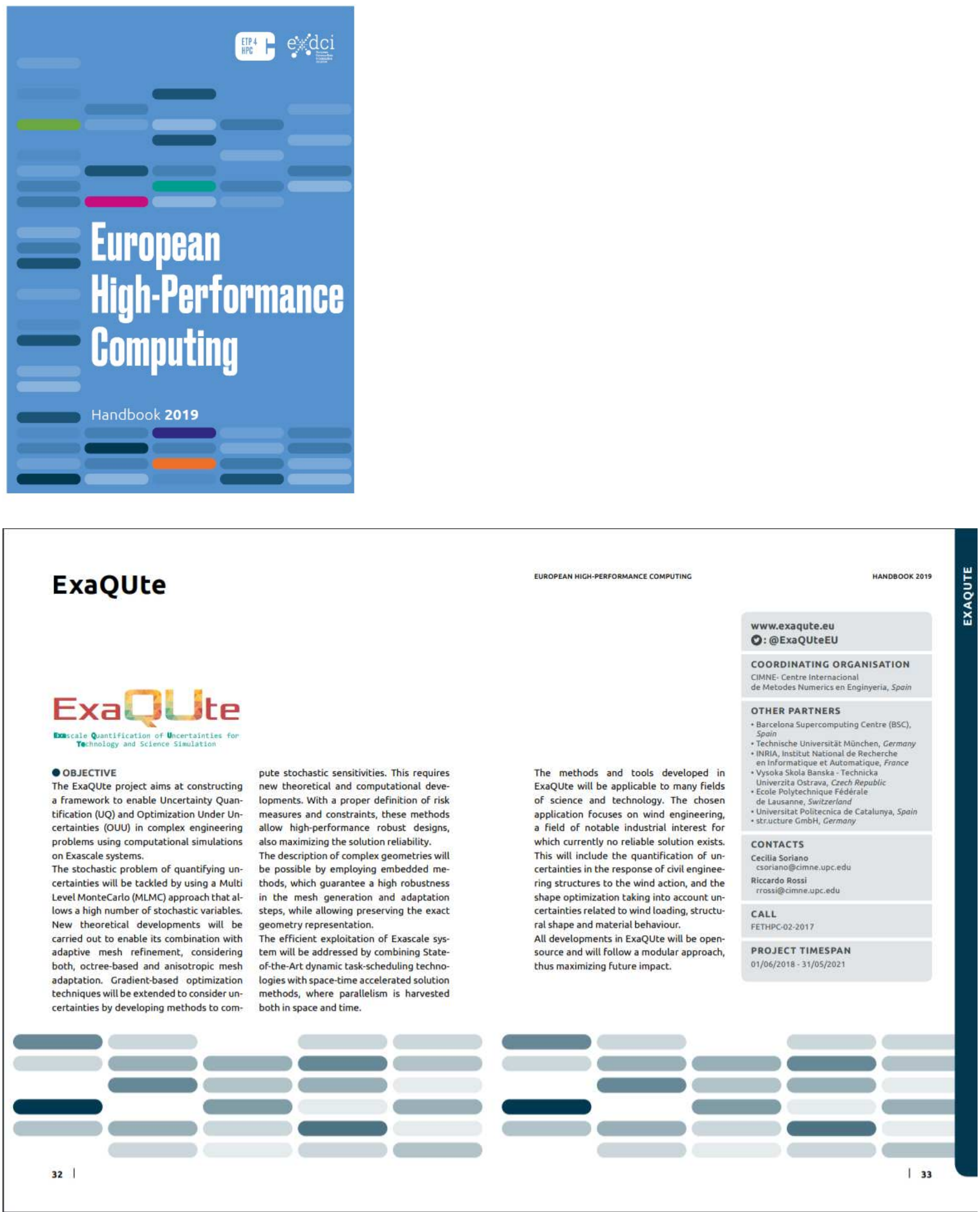


\subsubsection{SC 2019}

ExaQUte will be present at the SC Conference Series. SC19 will be held from Nov. 17-22 in Denver, www.supercomputing.org sharing the booth of the European Exascale project and Infrastructures group. The booth will be attended by project partners. BSC will also have its own booth where additional dissemination will be performed, as well as PyCOMPSs demonstrations. (photo booth (\#2215)

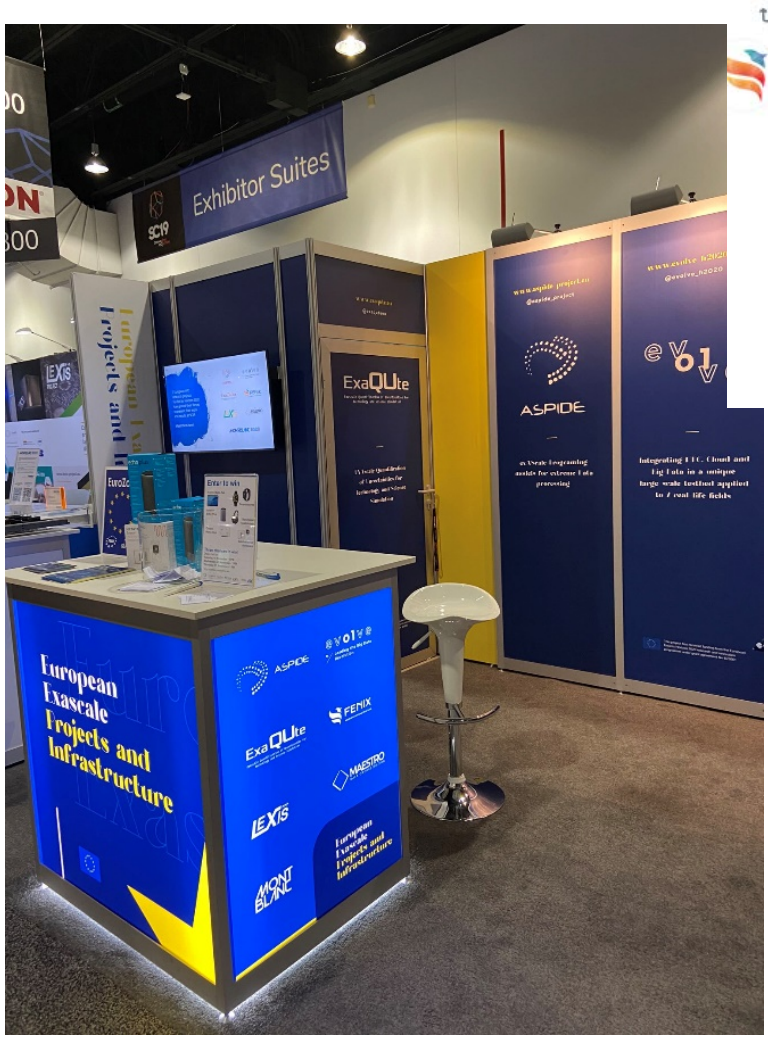

โ】 ExaQUte Retweeted

Fenix RI @Fenix_RI_eu. Oct 7

We're excited to participate in @Supercomputing 2019 along with @EU_H2020 \#Exascale projects. Find us at booth 2215 - More info on our joint page: bit.ly/2p0qql0 \#SC19 \#HPC

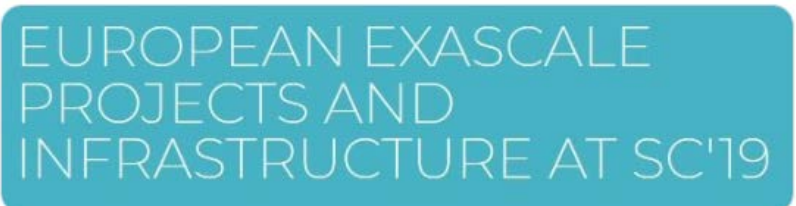

Iuropean Evascale Irojects and Infrastructure at SC19

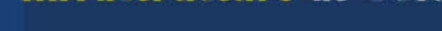

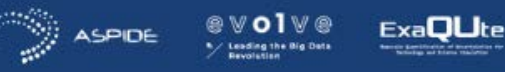

SFEMIX EXTÏ \MAESTRO MLNT

Rosa M. Badia@rosabadia.14h

Come and learn about @ExaQUteEU at the European \#Exascale projects booth \#2215 \#SC19 \#H2020

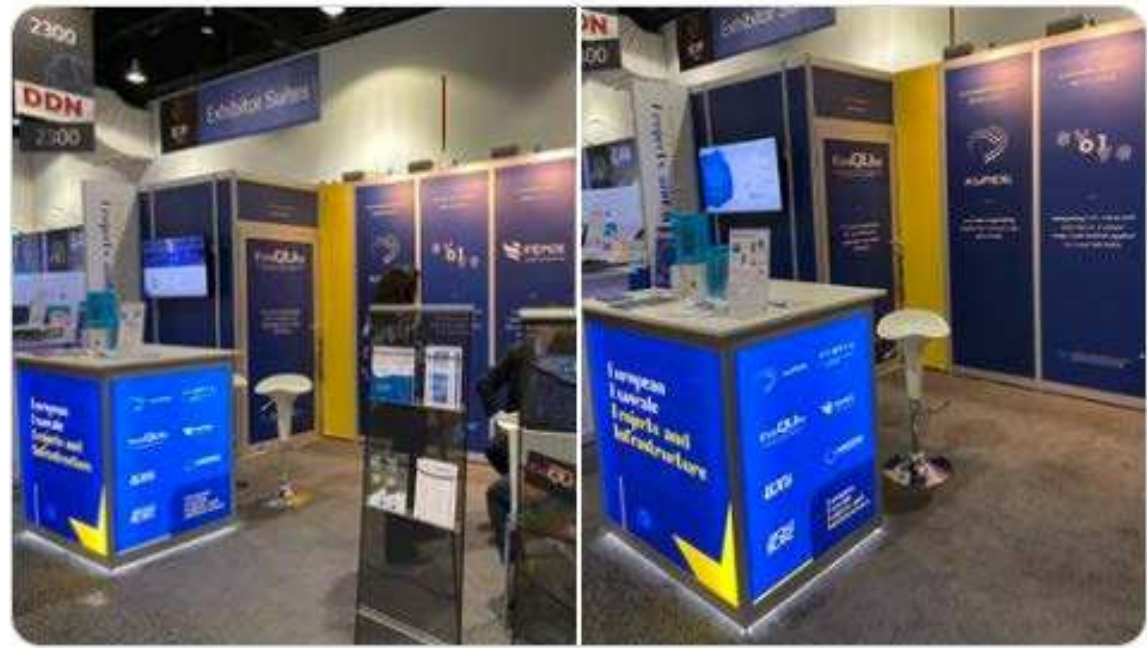

Figure 9 Common European Exascale Projects booth at ISC Conference 2019 


\subsubsection{Dr. Rosa Badia receives the ICT Woman Award}

The researcher of the Barcelona Supercomputing Center (BSC) Rosa M. Badia, and researcher of ExaQUte, has received the ICT Woman Award in the Academic / Researcher category granted by the Department of Digital Policies and Public Administration of the Generalitat de Catalunya.

This award recognizes the international projection of Badia's research work in the area of parallel programming models and its contribution to the promotion of women's participation in the ICT.

\section{CONGRATULATIONS Rosa!}
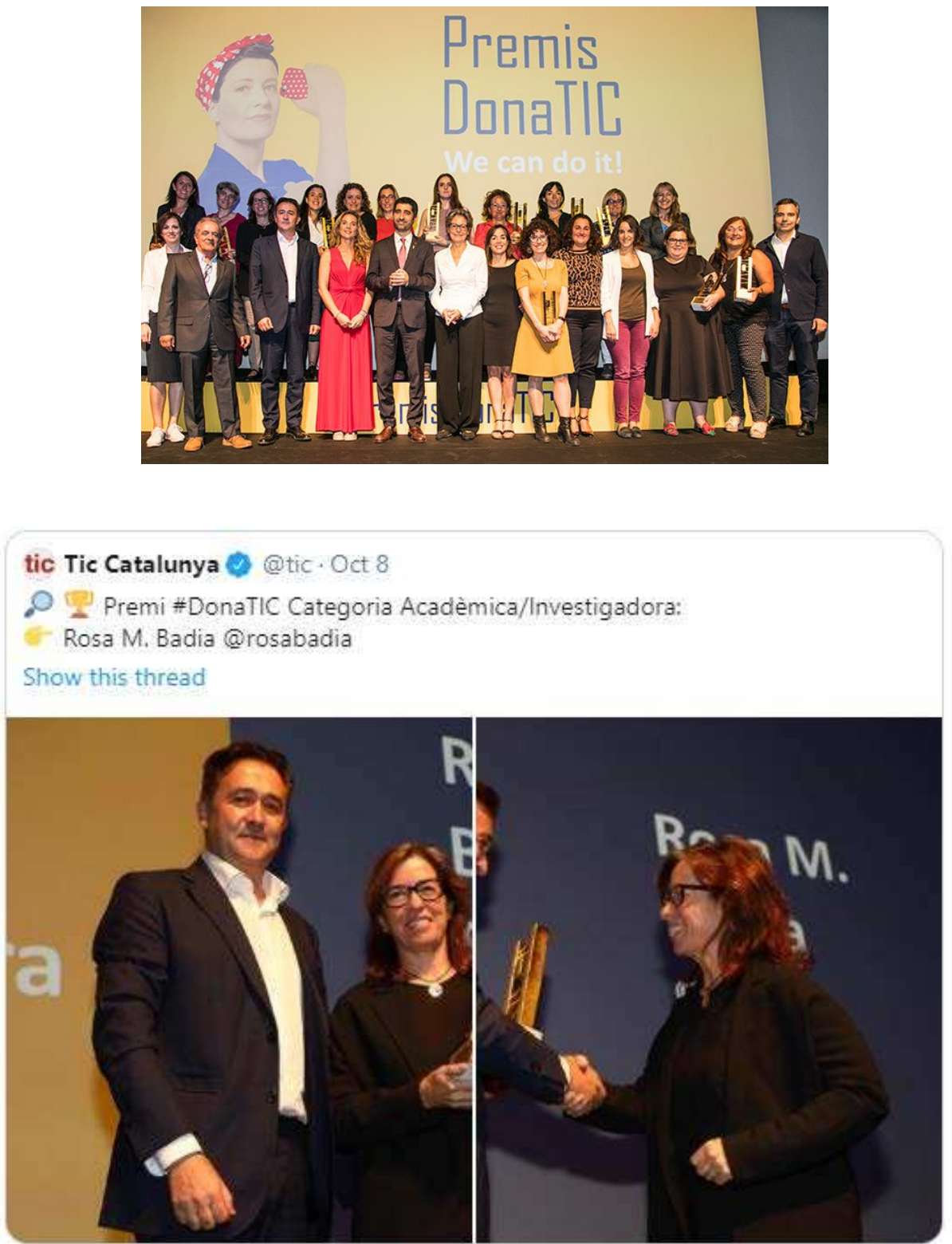

7:51 PM . Oct 8, 2019. Twitter for Android

Figure 10 Rosa Badia (ExaQUte/BSC) receives the ICT Woman Award granted by the Department of Digital Policies and Public Administration of the Generalitat de Catalunya 


\section{Open Source}

The ExaQUte project aims at constructing a framework to enable Uncertainty Quantification (UQ) and Optimization Under Uncertainties (OUU) in complex engineering problems, using computational simulations on Exascale systems. The methods and simulation tools developed in ExaQUte will be applicable to many fields of science and technology.

In particular, the chosen application focuses on wind engineering, a field of notable industrial interest. The problem to be solved has to do with the quantification of uncertainties in the simulation of the response of civil engineering structures to the wind action, and the shape optimization taking into account uncertainties related to wind loading, structural shape and material behavior.

The project entails the numerical simulations of heavy real engineering problems though the use of different codes and solvers that, given some input data, produce a file including the values of the relevant parameters that describe the results of the simulation of the original.

Firstly, ExaQUte has created an intranet, organized under GitLab repository at https://gitlab.com/principe/exaqute, a snapshot of which is shown in Fig. (11). This repository is used to share all working-in-progress documents and deliverables for the European Commission

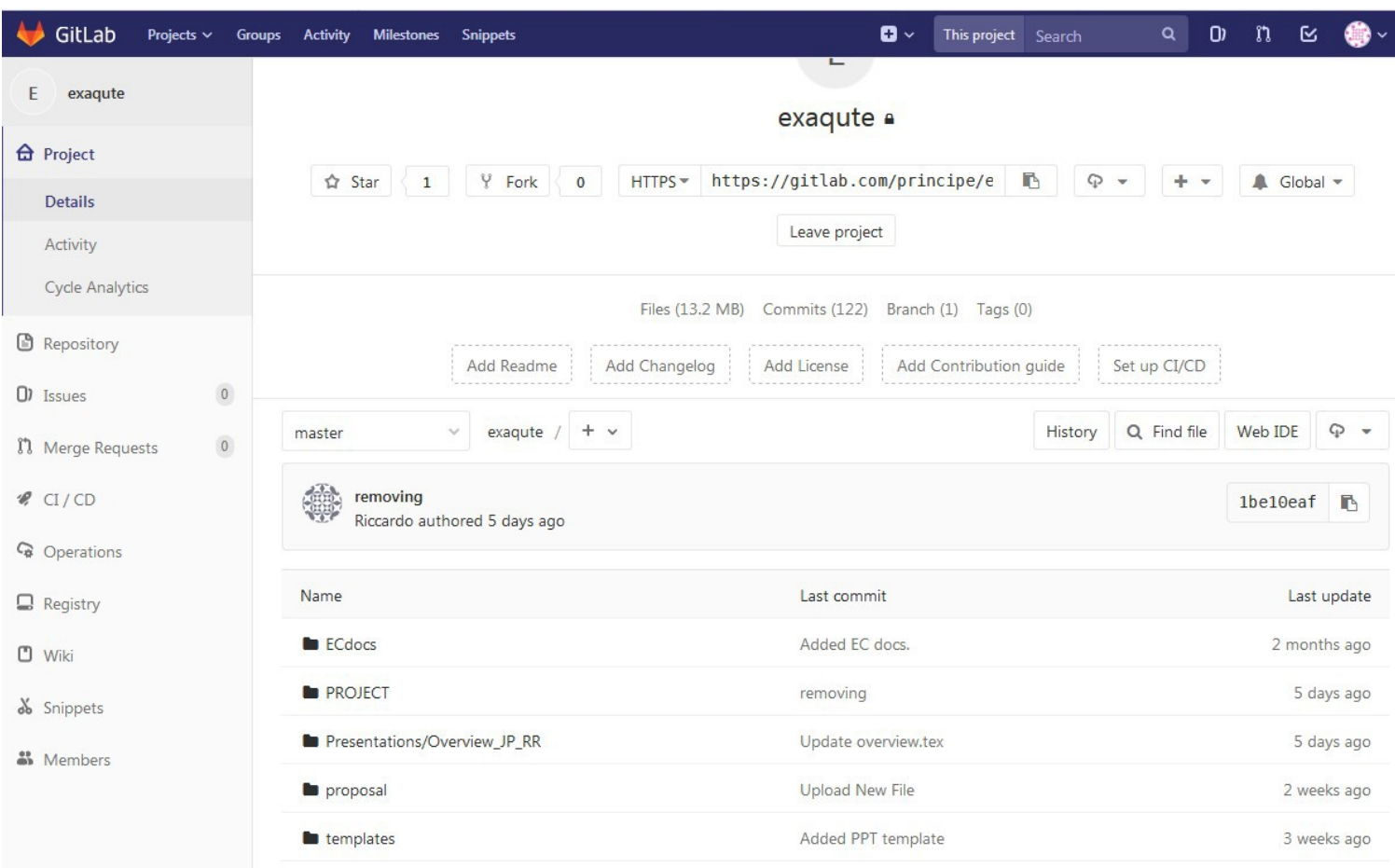

Figure 11: Git repository to share documents between partners

At the same time all the developments on fluid dynamics and optimization of ExaQUte will be integrated in the GitHub page of Kratos: https://github.com/KratosMultiphysics/Kratos (Fig. 4) which includes a wiki with the documentation of the project. On this platform, all the developments of ExaQUte will be integrated. 
Kratos adopts open standards for input and output formats, thus simplifying the exchange of data. In particular, a JSON (Java Script Object Notation) format is employed in the definition of the parameters defining the simulation. Simulation results can be stored either in proprietary ".post.bin" format (which can be opened by the GiD software) or in HDF5 format.

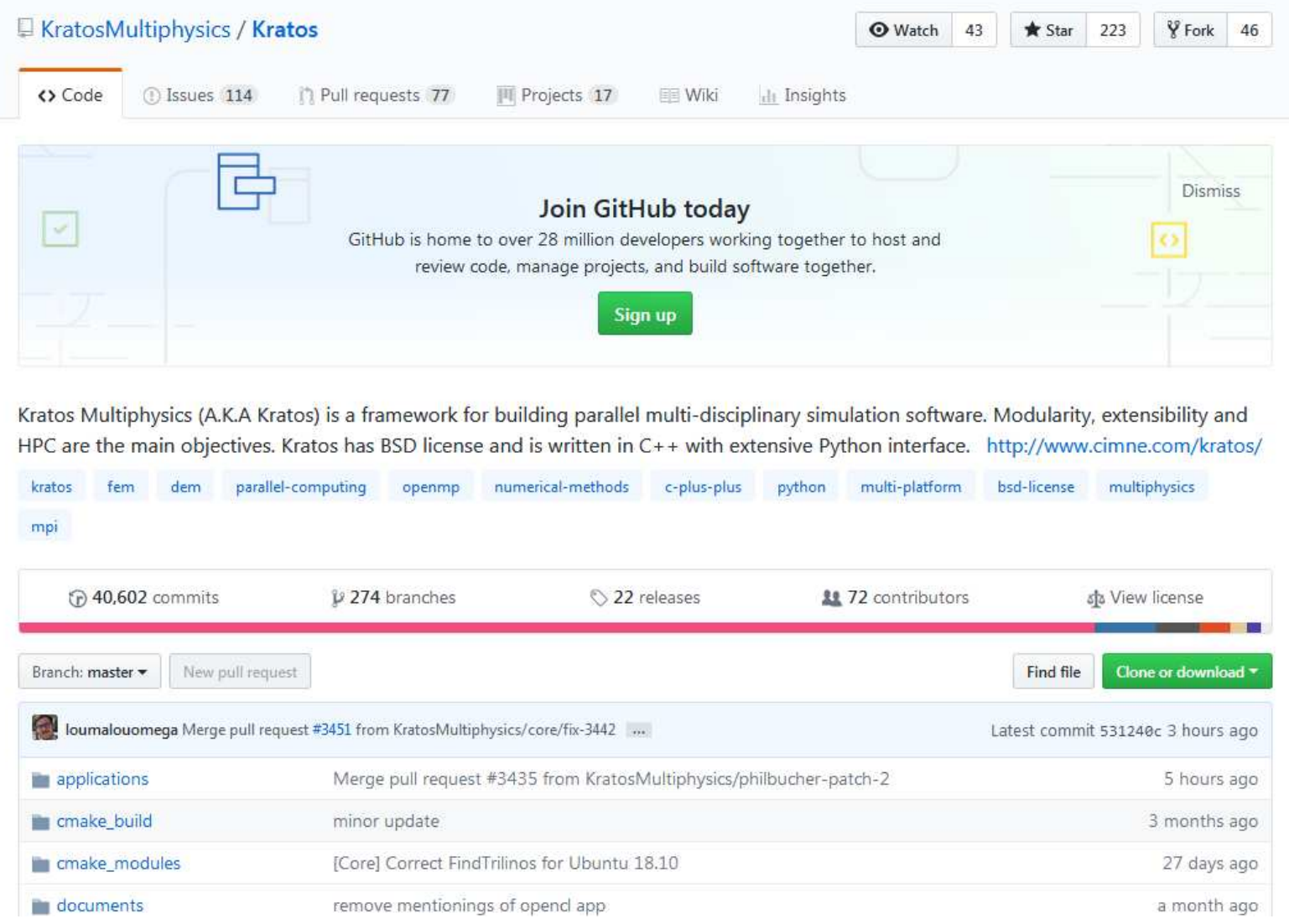

Figure 12: ExaQUte Code repository at GitHub

Time parallelization is under development on the FEMPAR solver, which is publically available in https://gitlab.com/fempar/fempar, and shown in the following figure.

In the project, a new collaborative library to develop new Monte Carlo algorithms to perform Uncertainty Quantification has been created, the XMC library: https://gitlab.com/RiccardoRossi/exaqute-xmc. The aim of this library is to contain all the capabilities to run Monte Carlo analysis on distributed environments. As a first approach, $\mathrm{XMC}$ uses Kratos as its main solver, but it is designed to be exploited in the future by any other solver. This software is under-development by BSC, CIMNE, EPFL. Although this repository is currently private, it will be soon public with the BSD license.

In addition, parallel computing is performed by using workflow management tools that allow to run multiple analyses in large scale environments. The workflow management tools used in the project are PyCOMPSs (https://github.com/bsc-wdc/compss), from BSC, and HyperLoom (https://github.com/It4innovations/HyperLoom), from IT4i. Both are publicly available in their respective repositories. 
fempar o

itropectio z260any

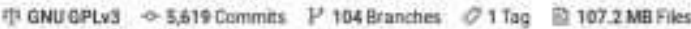

Finite Element Mutiphysics PAFiallis solves:

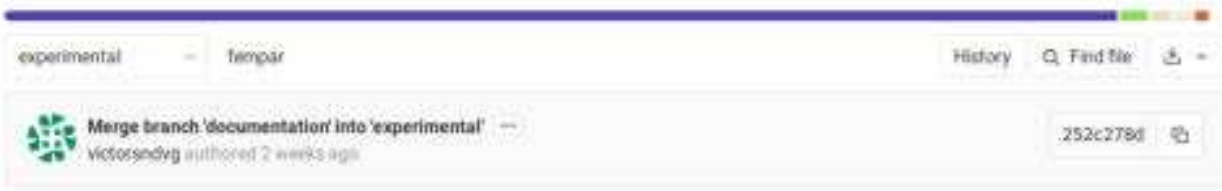

D REABES D cice contguration

\begin{tabular}{|c|c|c|}
\hline Name & Last compret & Last update \\
\hline achabs & Hambolnice anake remiages & 3 monthes so \\
\hline a Containers & 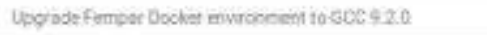 & 1 meinth-sigo \\
\hline a Dooumenti & 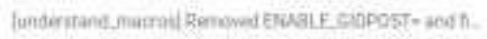 & 3 moncts 400 \\
\hline - Anvers & 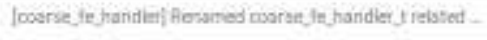 & Inonthus ayo \\
\hline W Prepos/tentpar gid & 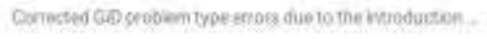 & -3 yearxase \\
\hline - Souves & Wodate HEAbuE ind faizat: & 3 monthas aps \\
\hline - Sugerbuld & 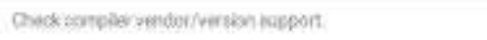 & 3 werds spt? \\
\hline b Throstianty & 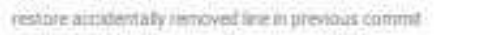 & X wredas ape \\
\hline a Tooks & 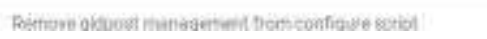 & 3inonchs ach \\
\hline
\end{tabular}

Riccardo , ExaQUte XMC, Details

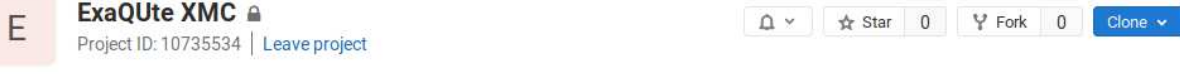

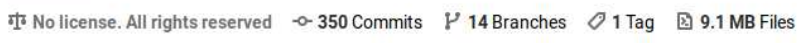

\begin{tabular}{|l|l|l|l|l|}
\hline master & History & Q Find file & Web IDE & む \\
\hline
\end{tabular}

G README

\begin{tabular}{|c|c|c|}
\hline Name & Last commit & Last update \\
\hline documentation & Merge branch 'master' of https://gitlab.com/Riccardo... & 5 months ago \\
\hline $\mathrm{xmc}$ & According to!14 (comment 189738751) in MR!14. & 3 weeks ago \\
\hline 国 gitignore & Merge branch 'master' of https://gitlab.com/Riccardo... & 5 months ago \\
\hline 国 README.md & Add empty README file & 8 months ago \\
\hline 国 README_STRUCTURE & Fixed a typo & 8 months ago \\
\hline - & According to!14 (comment 189738751) in MR !14. & 3 weeks ago \\
\hline 결 test_hierarchyOptimiser.py & Added test for hierarchy0ptimiser methods & 5 months ago \\
\hline 国 test_main_amc.py & Modifications in test scripts. Four algorithms are now... & 5 months ago \\
\hline 国 test_main_amc_Kratos.py & Modifications in test scripts. Four algorithms are now... & 5 months agc \\
\hline
\end{tabular}




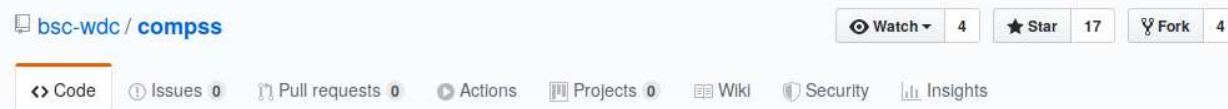

COMP Superscalar (COMPSs) is a framework which alms to ease the development and execution of applications for distributed Infrastructures, such as Clusters, Grids and Clouds.

distributed-computing workflows java python c workflow-management-system pipeline-framework hpc docker singularity slurm

\begin{tabular}{|c|c|c|c|c|c|c|c|}
\hline \multicolumn{2}{|c|}{ (1) 3,982 commits } & \multirow[t]{2}{*}{86 branches } & \multirow[t]{2}{*}{26 releases } & \multicolumn{2}{|c|}{ \& 15 contributors } & \multicolumn{2}{|c|}{ Apache-2.0 } \\
\hline Branch: stable - & New pull request & & & Create new flle & Upload flles & Find flle & Clone or downiload - \\
\hline \multicolumn{6}{|c|}{ Leroy Jenkins Update to version 2.6} & \multicolumn{2}{|c|}{ Latest commit b64656e 2 days ago } \\
\hline \multicolumn{2}{|c|}{ Iithub/ISSUE_TEMPLATE } & \multicolumn{4}{|c|}{ Update BUG and PR templates. Fix dependencies list on README.md } & & 10 months ago \\
\hline \multicolumn{2}{|c|}{. gittlab/issue_templates } & \multicolumn{4}{|c|}{ Update BUG and PR templates. Fix dependencies list on README.md } & & 10 months ago \\
\hline \multicolumn{2}{|l|}{ builders } & \multicolumn{4}{|c|}{ Update to version 2.6} & & 2 days ago \\
\hline \multicolumn{2}{|l|}{ compss } & \multicolumn{4}{|c|}{ Update to version 2.6} & & 2 days ago \\
\hline \multicolumn{2}{|c|}{ in dependencies } & \multicolumn{4}{|c|}{ Update extrae submodule (because of issues with the install script) } & & 11 days ago \\
\hline \multicolumn{2}{|l|}{ files } & \multicolumn{4}{|c|}{ removed: documentation folder } & & 5 months ago \\
\hline \multicolumn{2}{|c|}{ maven-plugins } & \multicolumn{4}{|c|}{ Update to version 2.6} & & 2 days ago \\
\hline \multicolumn{2}{|c|}{ - performance_analysis/auto-cbm } & \multicolumn{4}{|c|}{ Update to version 2.6} & & 2 days ago \\
\hline \multicolumn{2}{|l|}{ in tests } & \multicolumn{4}{|c|}{ Update to version 2.6} & & 2 days ago \\
\hline \multicolumn{2}{|l|}{ utils } & \multicolumn{4}{|c|}{ Update to version 2.6} & & 2 days ago \\
\hline \multicolumn{2}{|c|}{ 目 .dockerignore } & \multicolumn{4}{|c|}{ added: beta docker version with entrypoint } & & 11 months ago \\
\hline \multicolumn{2}{|l|}{ 目 .gitattributes } & \multicolumn{4}{|c|}{ moved binaries to lif } & & last year \\
\hline \multicolumn{2}{|l|}{ 目 .gitignore } & \multicolumn{4}{|c|}{ Update gitignore with new autoparallel files } & & last month \\
\hline
\end{tabular}

DIt4innovations / HyperLoom

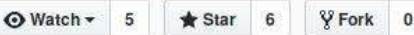

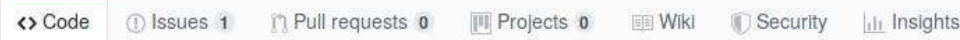

Platform for defining and executing scientific pipelines in distributed environments

distributed-systems hpc workflow pipellnes scheduler task

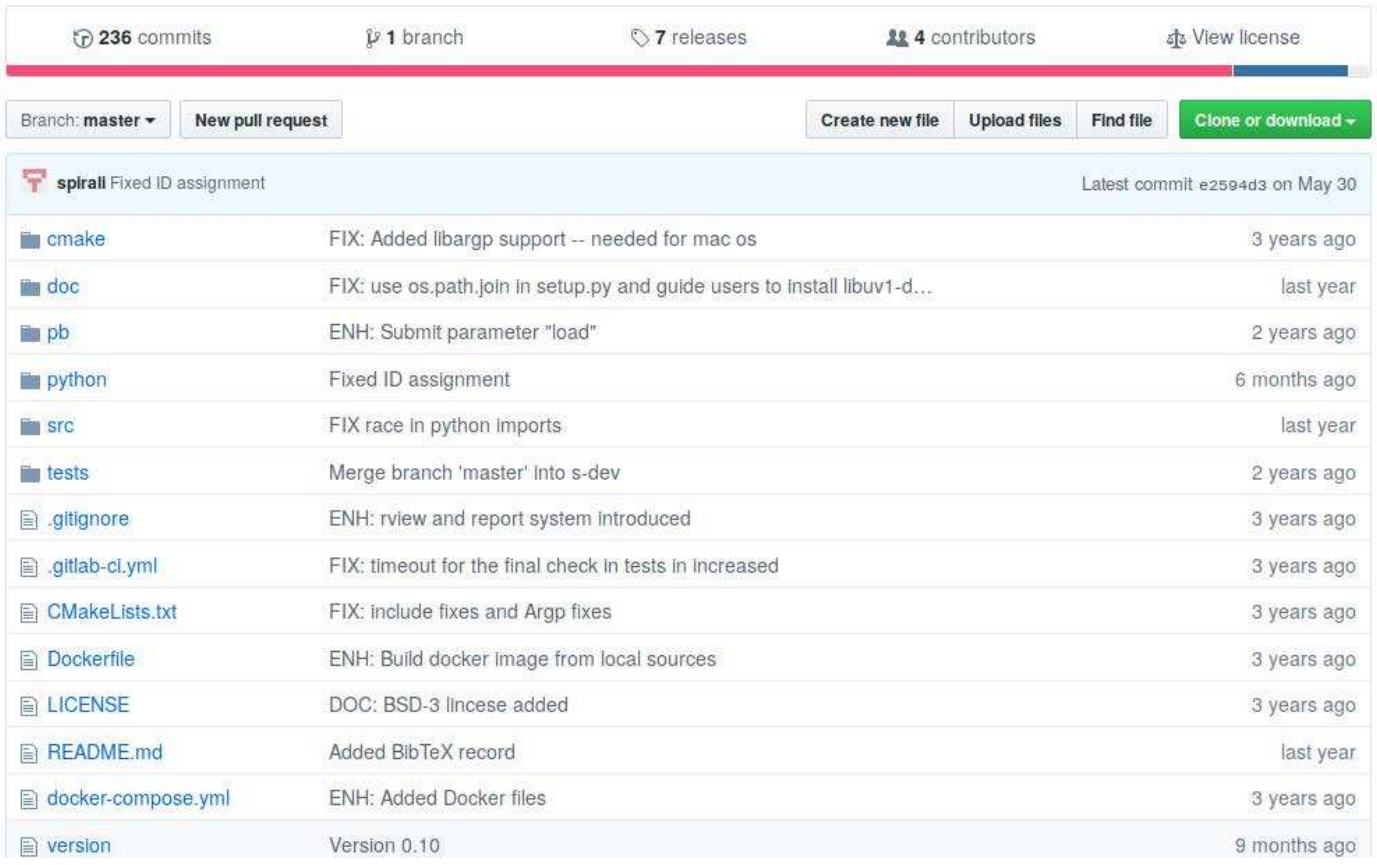




\section{Research Outcomes}

\subsection{Workshops and trainings}

\subsubsection{PATC training,}

PRACE, the Partnership for Advanced Computing in Europe appointed BSC as one of the PRACE Advanced Training Centre (PATC)

In this framework a training activity was delivered by the Workflows and Distributed Computing group at BSC (Barcelona, 29-30 January 2019) on the development of applications using the PyCOMPSs/COMPSs programming model.

The training is yearly organized under the PATC program. In this edition, the training was attended by multiple ExaQUte partners: EPFL, CIMNE, TUM, and BSC.

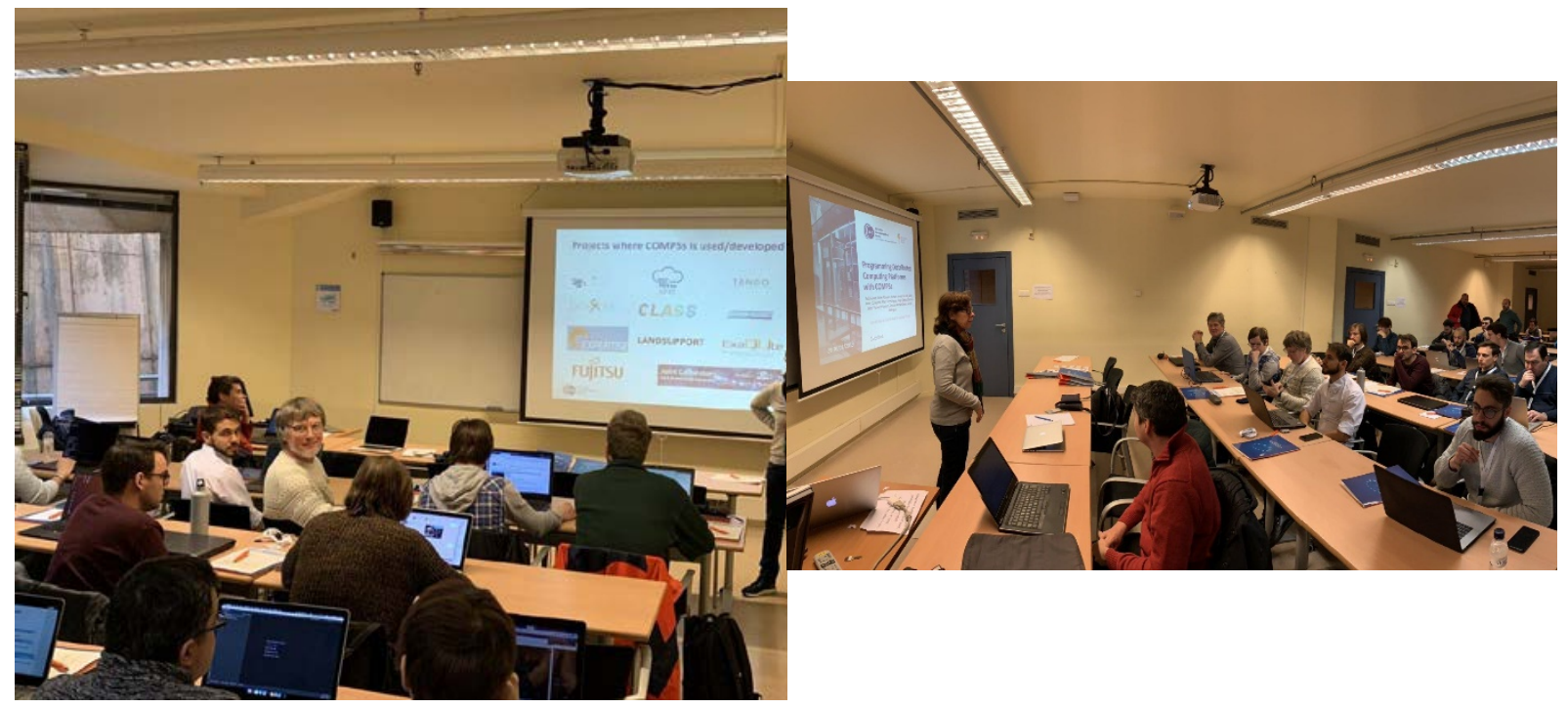

Figure 13: Training sessions on development of applications using the PyCOMPSs/COMPSs programming model

\subsection{2. $5^{\text {th }}$ Kratos Workshop}

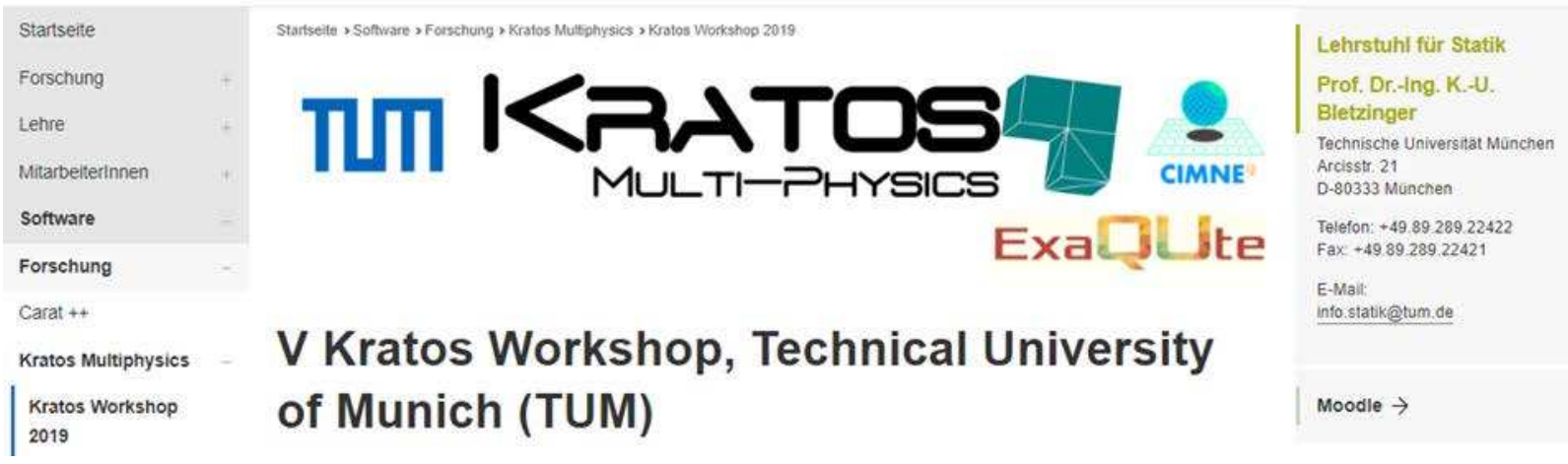


The fifth edition of the Kratos Workshop took place at the Technical University of Munich from the 25th to the 27th of March 2019.

The Kratos Workshop is the main meeting of users and developers of the Kratos Multiphysics open-source framework. Its goal is to bring together developers, industrial users and researchers to present new features in the code and discuss new and potential applications.

The main objectives of the workshop were:

- Give an overview on the open-source Multiphysics software project for potential future users and contributors.

- Provide forum for recent and (potential) future users and developers in research and industry.

- Improve the common knowledge of developers by presenting the latest features of the Kratos and solutions based on Kratos.

- Team building.

- In person discussions and contacts.

- Take advantage of round tables to discuss important issues and features.

- Dissemination of Kratos capabilities to local research centers and industries.

The workshop included Presentations about Kratos Multiphysics and its use in industrial and research applications, Discussion roundtables focusing on code design and development of new features, and a Hands-on Kratos Course. Siemens and Altair participated in the sessions dedicated to industrial Applications with Kratos SIEMENS $\triangle$ Altair

In addition, different talks were given to beginner users, to help them getting familiar with the software. Many ExaQUte members attended the workshop, and we took the chance to organize a progress meeting on the days following the workshop.

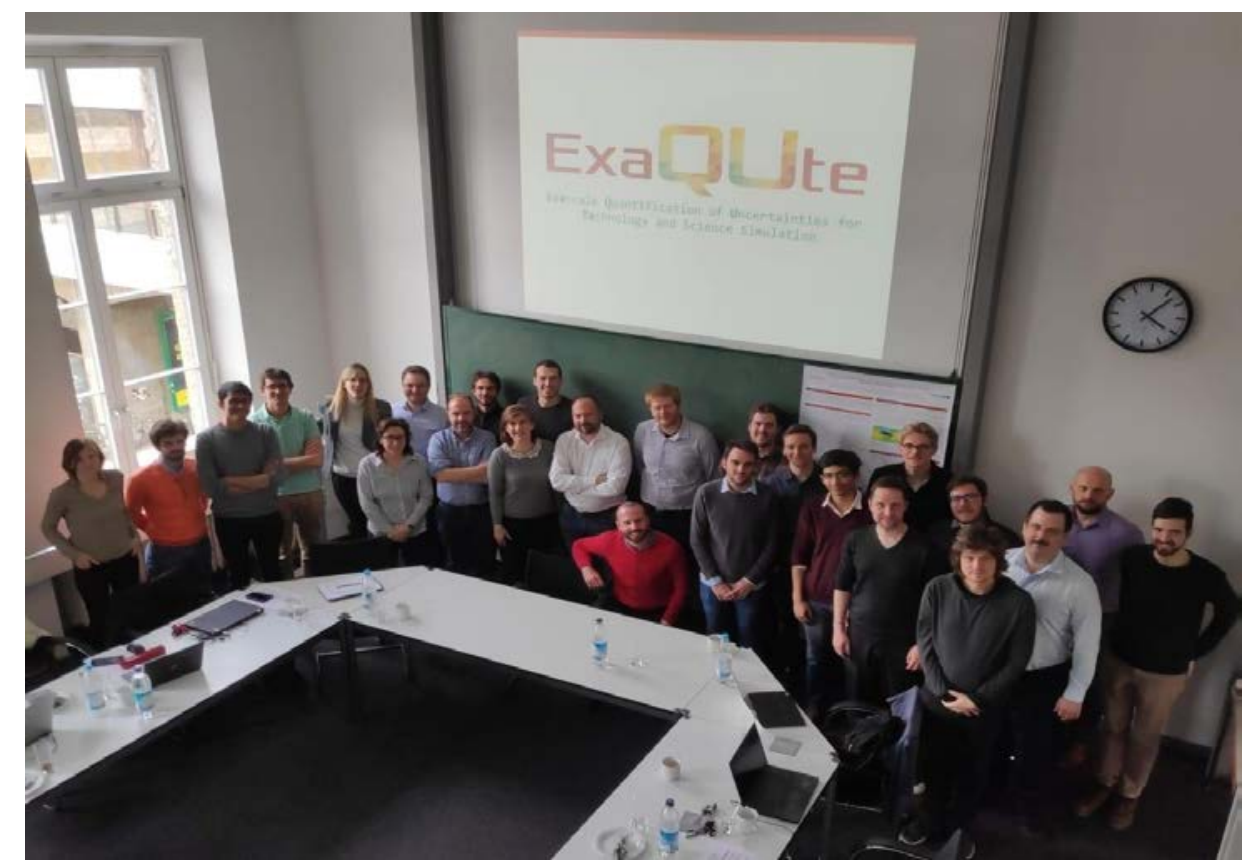

Figure 14: ExaQUte participants at the consortium meeting at TUM (Munich, Germany) 
4.1.3. EuroHPC Summit Week 2019 Poznan (Poland) 13-17 May 2019

ExaQute was present at EuroHPC Summit Week 2019 held in Poznan (Poland) on 13-17 May 2018 .

In this event, an ExaQUte poster was displayed and Rosa M Badia (BSC) was one of the presenters in the plenary on Wednesday, covering PyCOMPSs programming model aspects related to the project.

4.1.4. ISC Conference 2019 (Frankfurt 17-19 June)

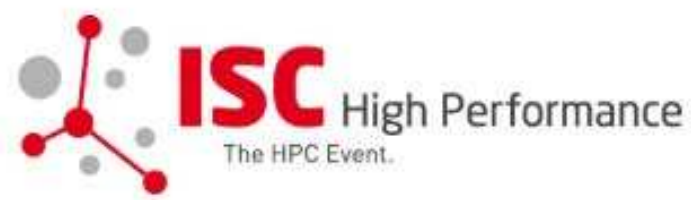

ExaQUte was present at ISC Conference 2019 in Frankfurt and joint the booth with other EC exascale projects.

The booth was attended by ExaQUte partners that were able to present initial project results and network with other ISC participants.

BSC also participated in that event with its own booth, where general dissemination about the project was delivered, as well as PyCOMPSs demonstrations
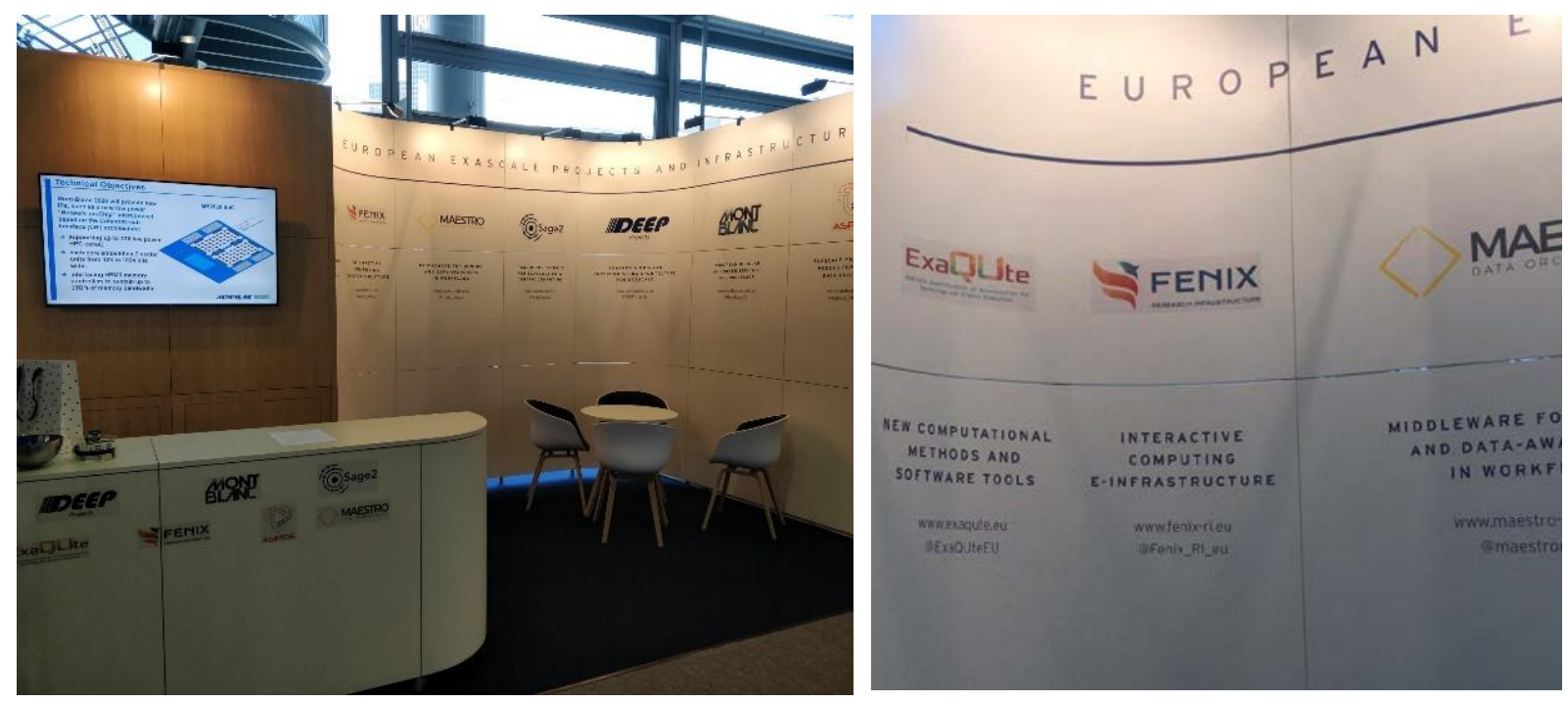

Figure 15: ExaQUte at the joint the booth EC exascale projects at ISC19 
4.1.5. International Congress on Industrial and Applied Mathematics (ICIAM)
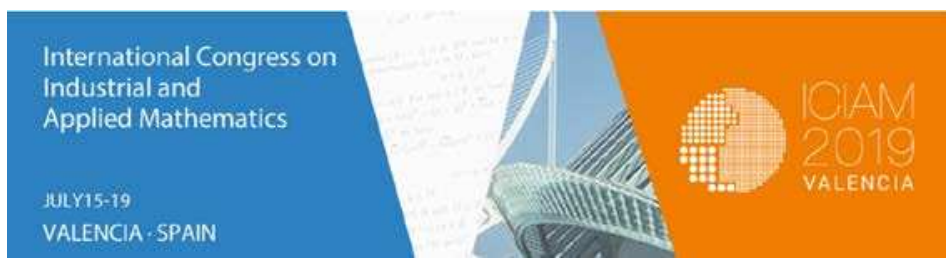

International Congress on Industrial and Applied Mathematics (ICIAM) Valencia (SPAIN), 15-19 July 2019

Fabio Nobile (EPFL) gave a presentation featuring ExaQUte in the mini-symposium 'Multifidelity methods for uncertainty quantification and optimization in complex systems', titled 'Accurate statistical estimators by continuation MLMC for engineering'.

4.1.6. US National Congress on Computational Mechanics (USNCCM)

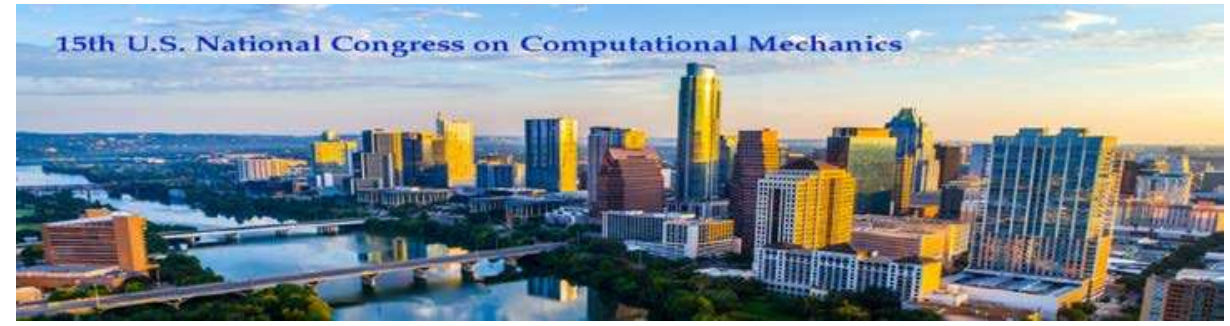

US National Congress on Computational Mechanics (USNCCM) Austin, TX, USA, Jul 28 August 1

Brendan Keith (TUM) resented research on risk-averse stochastic shape optimization of tall buildings; work done in collaboration with the ExaQUte partners at TUM and CIMNE. He gave an invited lecture at a minisymposium in honor of Professor Mary Wheeler.

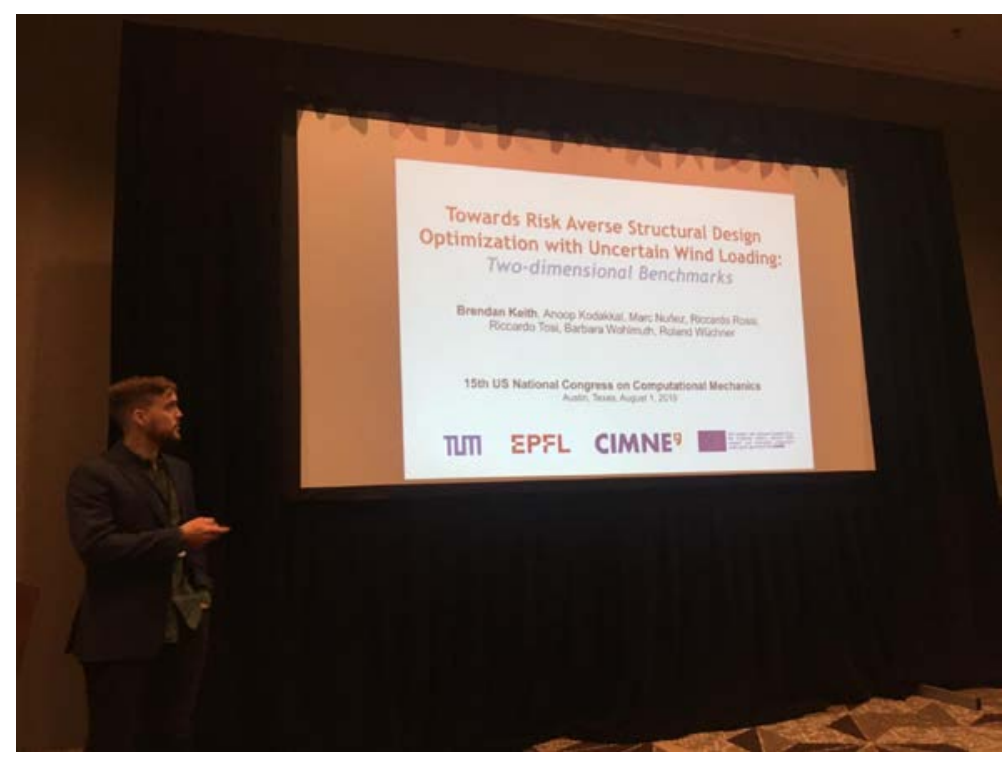

Figure 16: Brendan Keith (TUM) at USNCCM 


\subsubsection{Workshop FrontUQ}

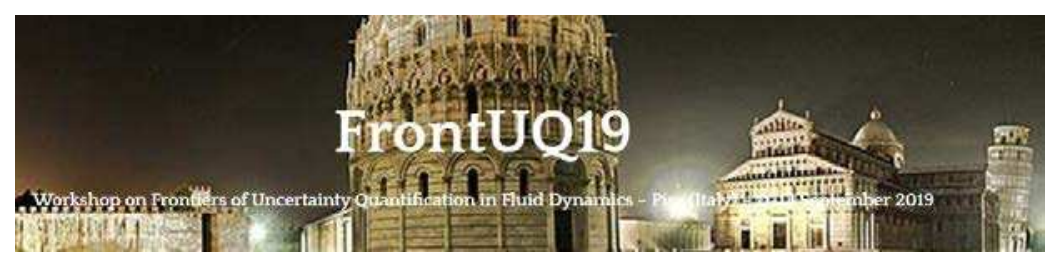

3nd workshop FrontUQ ( https://frontuq19.com/ ) Frontiers of Uncertainty Quantification in Fluid Dynamics. Held in Pisa (Italy) - 11-13 September 2019.

Participation of BSC, CIMNE, EPFL and TUM at the FrontUQ conference with three talks touching different ExaQUte topics.

- EPFL's talk centered on accurate statistical estimators for uncertain variables.

- CIMNE/BSC discussed and showed results of a recently-developed Monte Carlo method, designed for improving the computational cost improvement of when running in supercomputers.

- TUM/CIMNE's presentation focused on the parametric stochastic optimization of civil engineering buildings, influenced by the random behavior of wind.

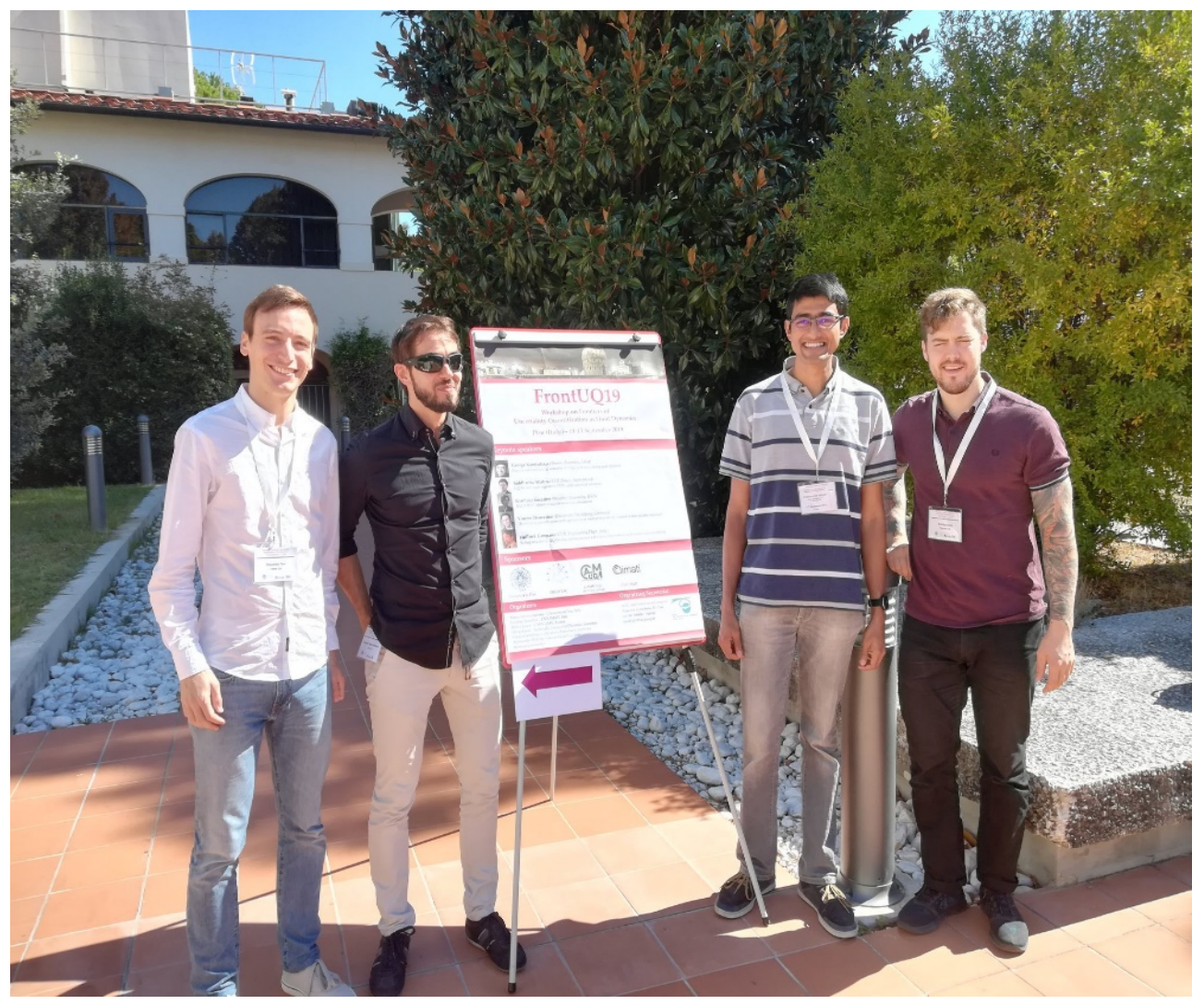

Figure 17: ExaQUte participants at the the FrontUQ Workshop 
4.1.8. RICAM Special Semester of Optimization

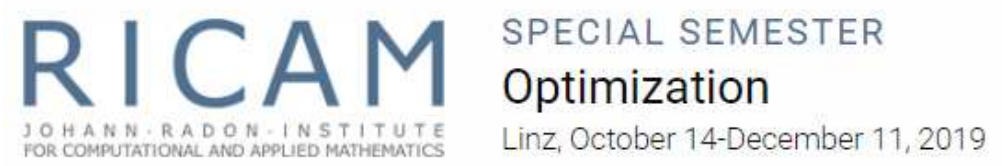

The RICAM (Radon Institute for Computational and Applied Mathematic) special semester on "Optimization" covers various aspects of optimization. Besides more classical themes like PDE-constrained and non-smooth optimization or feedback control the activities during the semester put a special focus on new trends and developments in this field like e.g. numerical methods for data science, influence of uncertainties, nonlocal effects or conic and copositive optimization

Quentin Ayoul-Guilmard (EPFL) presented a poster featuring ExaQUte, titled 'Multi-level Monte Carlo estimators for gradient-based optimization in engineering'.

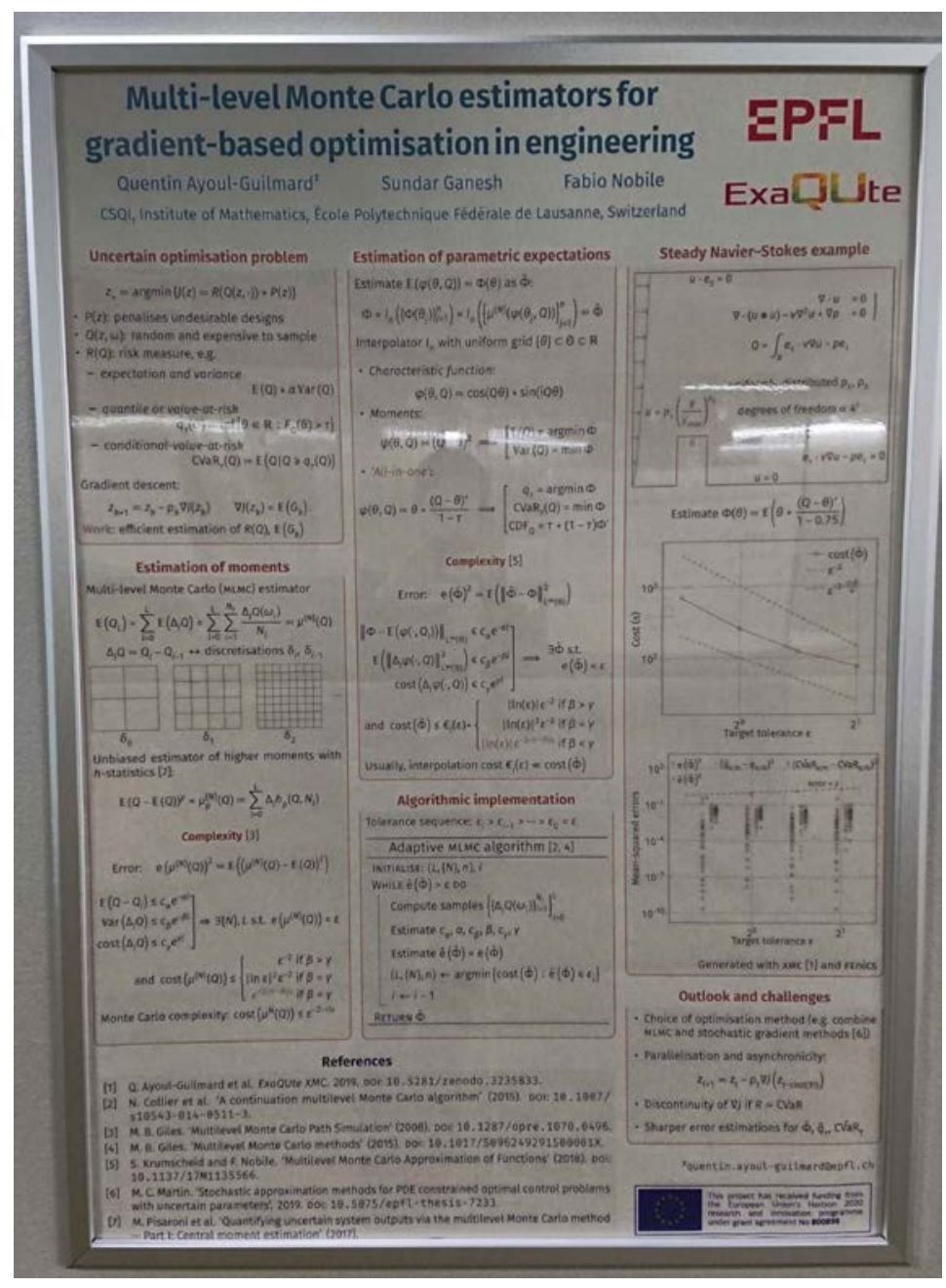

Figure 18: Poster at RICAM featuring ExaQUte 


\subsubsection{CIMNE Coffee Talks}

During the whole year CIMNE organizes coffee talks where researches have the chance to present their research developments.

On November 2019, Riccardo Tosi (CIMNE) presented research on workflow design of asynchronous Monte Carlo algorithms; work done in collaboration with the ExaQUte partners at BSC.

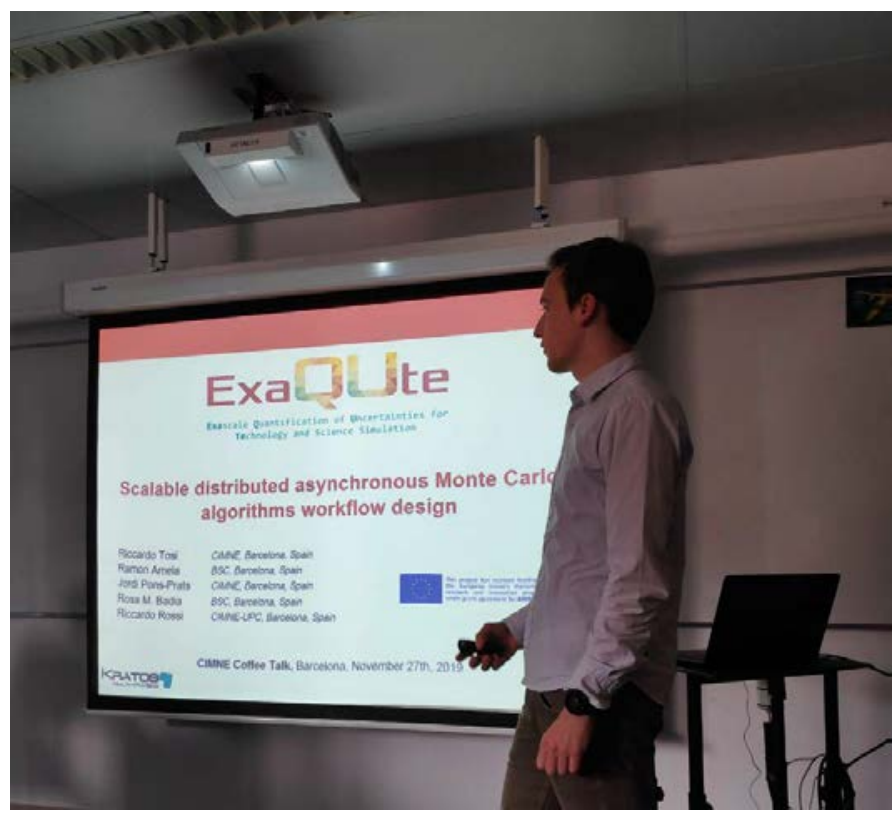

Figure 19: Riccardo Tosi (CIMNE) at CIMNE coffee talks

\subsection{Publications in journals and communications in conferences}

Scientific achievement in ExaQUte is planned to be disseminated using the standardized communication tools used in science and technology, mainly through publication of scientific and technical papers in relevant scientific journals and books

The publication of the project outcomes in peer-reviewed journal is a way to give confidence to potential users and to demonstrate the soundness of the work, supported by the scientific community.

As project coordinator, CIMNE has given instructions to all partners to remember to communicate always to the coordinator any publication related to the outcomes of the project and to always acknowledge the $\mathrm{EC}$ as a source of funding in their publications.

4.1.10. Journals

- Riccardo Tosi, Ramon Amela, Rosa M. Badia , Riccardo Rossi: "Scalable Dynamic asynchronous framework for Monte Carlo algorithms." SIAM Journal on Scientific Computing, 2019 (under review), https://www.siam.org/publications/journals/related/journal-policies/detail/open-access 
- Cristian Ramon-Cortes, Ramon Amela, Jorge Ejarque, Philippe Clauss, Rosa M. Badia “AutoParallel: Automatic parallelisation and distributed execution of affine loop nests in Python. "IEEE Transactions On Parallel and Distributed Systems, 2019 (under review),

- D Drzisga, B Keith, B Wohlmuth "The surrogate matrix methodology: a priori error estimation." SIAM Journal on Scientific Computing 2019 (in print)

- D Drzisga, B Keith, B Wohlmuth "The surrogate matrix methodology: Low-cost assembly for isogeometric analysis.". Computer Methods in Applied Mechanics and Engineering. 2019

- D Drzisga, B Keith, B Wohlmuth: The surrogate matrix methodology: A reference implementation for low-cost assembly in isogeometric analysis. MethoX 2019 (under review), (https://www.elsevier.com/journals/methodsx/2215-0161/open-access-journal)

- Francesc Verdugo, Alberto F. Martín, and Santiago Badia. "Distributed-Memory Parallelization of the Aggregated Unfitted Finite Element Method." Computer Methods in Applied Mechanics and Engineering 357 (2019): 112583. DOI $=\{10.1016 /$ j.cma.2019.112583 $\}$

- Santiago Badia, Alberto F. Martín, Eric Neiva and Francesc Verdugo "A generic finite element framework on parallel tree-based adaptive meshes." ACM Transactions on Mathematical Software (TOMS) DOI $=\{$ arXiv: 1907.03709$\}$.

- Santiago Badia, Jerrad Hampton, Javier Principe "Embedded multilevel Monte Carlo for uncertainty quantification in random domains." (2019) International Journal for Uncertainty Quantification (Under review)

\subsubsection{Conferences}

- Riccardo Tosi, Ramon Amela , Jordi Pons-Prats, Rosa M. Badia, Riccardo Rossi. "Scalable distributed asynchronous Monte Carlo algorithms workflow design." Conference proceedings/Workshop frontUQ: https://frontuq19.com/.11-13 September 2019

- F. Nobile, Q. Ayoul-Guilmard, S. Ganesh "Accurate statistical estimators by continuation MLMC for engineering design problems." Conference proceedings/Workshop frontUQ: https://frontuq19.com/.11-13 September 2019

- B. Keith, A. Kodakkal, M. Nuñez, R. Rossi, R. Tosi, B.Wohlmuth, and R.Wüchner "Towards risk averse structural design optimization with uncertain wind loading: Two-dimensional benchmarks." Conference proceedings/Workshop frontUQ: https://frontuq19.com/.11-13 September 2019

- B. Keith, A. Kodakkal, M. Nuñez, R. Rossi, R. Tosi, B.Wohlmuth, and R.Wüchner "Towards risk averse structural design optimization with uncertain wind loading: Two-dimensional benchmarks." Conference proceedings/Workshop USNCCM: https://http://15.usnccm.org/ . 28 September - August 1,2019

- I Lopez, R. Rossi, P. Dadvand, K.U. Bletzinger and R. Wüchner. "A Cut Finite-Element Method for Compressible Subsonic Flow with an Embedded Wake Approach for Coupled Aeroelastic Optimization of Flexible Wing Structures." VIII International Conference on Coupled Problems in Science and Engineering

- F. Verdugo, A. F. Martín, and S. Badia, "Simplifying mesh generation in large-scale simulations via embedded finite elements". (invited session). International Congress on Industrial and Applied Mathematics (ICIAM 2019), Valencia, Spain, July 2019.

- F. Verdugo, A. F. Martín, and S. Badia, "Implementation and performance of the aggregated unfitted finite element method at large scales." (invited session), Congress on Numerical Methods in Engineering (CMN2019), Guimarães, Portugal, July 2019. 
- P. A. Martorell, F. Verdugo, and S. Badia, "Integration technique for Unfitted Finite Element Methods on 3D CAD defined domains." (invited session), VII International Conference on Computational Methods for Coupled Problems in Science and Engineering (COUPLED PROBLEMS 2019), Sitges, Spain, June 2019.

- F. Verdugo, A. F. Martín, and S. Badia, "Large-scale embedded domain simulations by means of the AggFEM method." (invited session), VII International Conference on Computational Methods for Coupled Problems in Science and Engineering (COUPLED PROBLEMS 2019), Sitges, Spain, June 2019.

- S. Badia, J. Hampton, J. Principe "Embedded multilevel Monte Carlo for uncertainty quantification in random domains." (2019). 15th U.S. National Congress on Computational Mechanics. July 28 August 1, 2019, Austin, Texas, USA. Page 601. http://15.usnccm.org/sites/default/files/USNCCM15\%20Abstracts.pdf .

- S. Badia, J. Hampton, J. Principe. Embedded multilevel Monte Carlo for uncertainty quantification in random domains. COUPLED PROBLEMS 2019 VIII International Conference on Computational Methods for Coupled Problems in Science and Engineering. 3-5 June 2019 in Sitges, Spain. https://congress.cimne.com/coupled2019/frontal/doc/EbookCoupled2019.pdf

- S. Badia, A. F. Martín, F. Verdugo, “Aggregated Unfitted Finite Element Methods for Large Scale Simulations on Octree Meshes". (invited session), 13th World Congress on Computational Mechanics (WCCM XIII), New York, United States of America, July 2018. 